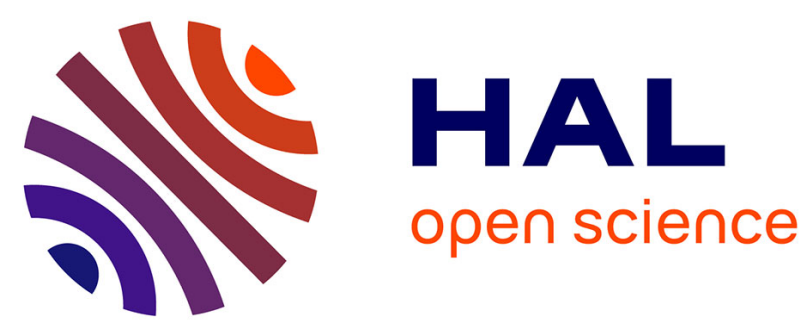

\title{
Deriving Amorphous Component Abundance and Composition of Rocks and Sediments on Earth and Mars
}

Rebecca J. Smith, Elizabeth B. Rampe, Briony H. N. Horgan, Erwin Dehouck

\section{To cite this version:}

Rebecca J. Smith, Elizabeth B. Rampe, Briony H. N. Horgan, Erwin Dehouck. Deriving Amorphous Component Abundance and Composition of Rocks and Sediments on Earth and Mars. Journal of Geophysical Research. Planets, 2018, 123 (10), pp.2485-2505. 10.1029/2018JE005612 . hal-02326508

\section{HAL Id: hal-02326508 \\ https://univ-lyon1.hal.science/hal-02326508}

Submitted on 3 Jan 2022

HAL is a multi-disciplinary open access archive for the deposit and dissemination of scientific research documents, whether they are published or not. The documents may come from teaching and research institutions in France or abroad, or from public or private research centers.
L'archive ouverte pluridisciplinaire HAL, est destinée au dépôt et à la diffusion de documents scientifiques de niveau recherche, publiés ou non, émanant des établissements d'enseignement et de recherche français ou étrangers, des laboratoires publics ou privés.

$$
\text { Copyright }
$$




\section{Journal of Geophysical Research: Planets}

\section{RESEARCH ARTICLE \\ 10.1029/2018JE005612 \\ Key Points: \\ Deriving Amorphous Component Abundance and Composition of Rocks and Sediments on Earth and Mars}

- Amorphous abundance estimates from different methods can vary significantly for a single sample

- Mass balance calculations can help determine the accuracy of mineralogy models and amorphous abundance and composition estimations

- Amorphous composition estimates from the CheMin instrument on Mars are likely accurate

Supporting Information:

- Supporting Information S1

- Table S1

- Data Set S1

Correspondence to:

R. J. Smith,

rebeccajsmith@purdue.edu

\section{Citation:}

Smith, R. J., Rampe, E. B., Horgan, B. H. N., \& Dehouck, E. (2018). Deriving amorphous component abundance and composition of rocks and sediments on Earth and Mars. Journal of Geophysical Research: Planets, 123, 2485-2505. https://doi.org/10.1029/2018JE005612

Received 15 MAR 2018

Accepted 7 SEP 2018

Accepted article online 13 SEP 2018

Published online 4 OCT 2018

Author Contributions:

Conceptualization: Rebecca J. Smith, Elizabeth B. Rampe, Briony H. N. Horgan Formal analysis: Rebecca J. Smith, Elizabeth B. Rampe

Investigation: Rebecca J. Smith, Elizabeth B. Rampe

Methodology: Rebecca J. Smith, Elizabeth B. Rampe, Erwin Dehouck Resources: Elizabeth B. Rampe, Briony H. N. Horgan

Supervision: Briony H. N. Horgan Visualization: Rebecca J. Smith Writing - original draft: Rebecca J. Smith

Writing - review \& editing: Rebecca J. Smith, Elizabeth B. Rampe, Briony H. N. Horgan, Erwin Dehouck

\author{
Rebecca J. Smith ${ }^{1}$ (D), Elizabeth B. Rampe ${ }^{2}$ D, Briony H. N. Horgan ${ }^{1}$ iD, and Erwin Dehouck ${ }^{3}$ \\ ${ }^{1}$ Department of Earth, Atmospheric, and Planetary Sciences, Purdue University, West Lafayette, IN, USA, ${ }^{2}$ NASA/Johnson \\ Space Center, Houston, TX, USA, ${ }^{3}$ Laboratoire de Géologie de Lyon-Terre, Planètes, Environnement, UMR 5276, CNRS, \\ Université Lyon 1, ENS Lyon, Villeurbanne, France
}

Abstract X-ray amorphous materials have been detected in all samples measured by the CheMin X-ray diffractometer (XRD) on board the Mars Science Laboratory rover in Gale Crater, Mars. The origin(s) of these materials are poorly understood, and there are significant uncertainties on their estimated abundances and compositions. Three methods are used to estimate the bulk amorphous component abundance and composition of Martian samples using XRD and bulk chemical data: (1) Rietveld refinements, (2) FULLPAT analyses, and (3) mass balance calculations. We tested these methods against a quantitative XRD (internal standard) method commonly used in terrestrial laboratories. Additionally, we tested for instrumentation effects by measuring our samples on a laboratory XRD instrument (PANalytical X'Pert Pro) and the CheMin test bed instrument (CheMin IV). We used three natural samples known to contain amorphous materials: glacial sediment, Hawaiian soil, and a paleosol. Our methods resulted in nine amorphous abundances and four amorphous compositions for each sample. For a single sample, amorphous abundance estimates and amorphous compositions are relatively similar across all estimation methods. CheMin analog measurements perform well in our tests, with amorphous abundances and compositions comparable to laboratory quantitative XRD measurements, though slightly underestimated. This suggests that previous amorphous component estimates for Martian samples are relatively accurate. This study highlights the usefulness of the mass balance calculation method for characterizing amorphous materials in terrestrial samples, providing important supplemental information to destructive and time consuming size separation and dissolution procedures.

Plain Language Summary Natural soil and sediment samples on Earth and Mars are commonly mixtures of crystalline and noncrystalline materials. X-ray diffraction techniques are frequently used to quantify the abundance and composition of crystalline materials, and relatively recent developments in X-ray diffraction data analysis methods allow noncrystalline materials to also be characterized. Noncrystalline materials are studied using the following methods: (1) noncrystalline X-ray diffraction peaks modeled with broad peaks, (2) noncrystalline peaks modeled with diffraction patterns of measured noncrystalline materials, and (3) a mass balance calculation that combines chemical and X-ray diffraction data. However, it is uncertain how accurate these methods are. Here we systematically test these three data analysis methods on complex natural samples. We find that both modeling methods ( 1 and 2 ) are capable of providing relatively accurate noncrystalline component abundances. Modeling noncrystalline peaks with patterns of measured noncrystalline materials (method 2) provides the most accurate abundance results but does not necessarily provide accurate compositional information, whereas the mass balance calculation provides accurate noncrystalline material compositions, but not abundances. Our results suggest that a combination of methods (either 1 and 3 or 2 and 3 ) should be used to more completely characterize the abundance and composition of noncrystalline materials.

\section{Introduction}

X-ray amorphous materials have been detected at high abundances ( 15-70 wt\%) in all rock and soil samples measured by the CheMin X-ray diffractometer (XRD) instrument onboard the Mars Science Laboratory (MSL) rover in Gale Crater, Mars (Achilles, Downs, Ming, et al., 2017; Achilles, Downs, Rampe, et al., 2017; Bish et al., 2013; Morris et al., 2016; Rampe, Ming, et al., 2017; Vaniman et al., 2014; Yen et al., 2017). X-ray amorphous 
materials lack long range crystallographic order and can be formed in a number of geologic settings, through a variety of processes, including volcanic, impact, and aqueous alteration (e.g., Birrell \& Fieldes, 1952; De Mumbrum, 1960; Ishii \& Mori, 1959; Mitchell \& Farmer, 1960; Schwertmann \& Fischer, 1973; Simas et al., 2006; Sudo, 1954). In general, amorphous materials form during rapid processes such as quenching of magma in water, rapid precipitation of solutes, or rapid pedogenic leaching (Ziegler et al., 2003). The amorphous materials on Mars could be any combination of primary (e.g., glass) and secondary (e.g., silica and ferrihydrite) phases. In order to constrain the types of geologic processes that have occurred on the Martian surface, it is necessary to evaluate the techniques used by the rover to characterize their abundance and composition and to develop a better understanding of the abundances and compositions of terrestrial amorphous materials in general.

The fluviolacustrine and eolian samples analyzed by CheMin contain a mixture of crystalline and amorphous materials; however, the abundance of the amorphous component is difficult to constrain, because its presence is only expressed in XRD patterns by very broad and low-intensity peaks. For example, the amorphous component of the Rocknest eolian soil sample has been estimated at $35 \mathrm{wt} \%$, but with a relative uncertainty of $15 \%$, which gives a range of 20 to 50 wt\% (Achilles, Downs, Ming, et al., 2017). Amorphous materials are significant components of the surface in this region of Mars, and understanding their origin has important implications for our understanding of the evolution of the Martian surface. One hypothesis to explain the prevalence of amorphous materials on Mars is that the geologic process (es) that form and/or preserve the X-ray amorphous materials in Martian samples may be unique to Mars. Yet comparable fractions of amorphous components have been reported in volcanic soils on Earth (e.g., Jones et al., 2000). This observation suggests that similar processes may have also occurred on Earth, and we can investigate these ambiguous materials using MSL characterization techniques and terrestrial analogs.

A number of techniques are used to quantify weight percent abundances in multicomponent samples on Earth and Mars. For XRD data, full-pattern fitting methods alone (i.e., Rietveld refinements, FULLPAT) can quantify absolute crystalline abundances if the sample does not contain an X-ray amorphous component. However, if the sample does contain an X-ray amorphous component, as is the case on Mars, we must make assumptions about the scattering power of the amorphous material (which is related to its composition and structure) before we can quantify its abundance and obtain absolute crystalline abundances. In labs on Earth, we can avoid making assumptions about the amorphous material by including a known amount of an internal standard in the sample during preparation (e.g., Alexander \& Klug, 1948, Chung, 1974, Copeland \& Bragg, 1958, Hooton \& Giorgetta, 1977, Klug \& Alexander, 1974). The XRD pattern of the sample and standard mixture is then measured, and the ratio of the known to the modeled abundance of internal standard is used to scale the modeled phase abundances to their actual abundance in the mixture. The crystalline abundances are then summed, and any difference from $100 \%$ is attributed to an amorphous component. However, because of limitations on sample preparation in the automated MSL sample delivery system, the CheMin instrument on MSL does not include an internal standard in its samples, and so the amorphous abundances remain dependent on assumed material properties.

X-ray amorphous abundances as well as compositions have been estimated from CheMin XRD data using a mass balance calculation (MBC), which combines both the crystalline mineralogy derived from full-pattern fitting analyses of CheMin data and the bulk chemical composition measured by the Alpha Particle X-Ray Spectrometer instrument (APXS; Gellert et al. $(2006,2015)$ ). In this method, the crystalline composition, calculated from the XRD-derived mineralogy, is subtracted from the bulk chemical composition, and the amorphous component is assumed to account for the difference (e.g., Dehouck et al., 2014, Morris et al., 2013, Vaniman et al., 2014). Since this method relies on careful analysis of the crystalline components, any errors in the fitting will propagate into the MBC estimates.

Methods that estimate amorphous abundances and compositions have not been rigorously tested on natural samples using the CheMin test bed instrument. In this study, we test the accuracy of both the full-pattern fitting XRD analysis methods (FULLPAT and Rietveld refinement) and the MBC method for deriving amorphous abundances from samples without an internal standard by applying these methods to three different Mars analog terrestrial samples known to contain amorphous materials. For each method, we test how the estimated amorphous abundances and compositions vary with and without an internal standard included in the XRD data acquisition and how the composition of the sample affects the accuracy of the results. This information will help determine best practices for 
estimating the abundance and composition of amorphous components both in labs on Earth and with MSL on Mars, including ideal instrument setup parameters, sample processing steps, and XRD data analysis and refinement techniques.

\section{Background}

\subsection{Evidence for Amorphous Materials in MSL Data}

The presence of an X-ray amorphous component can be inferred from XRD patterns by the appearance of a low angle rise $\left(<\sim 10^{\circ} 2 \theta\right)$ and/or broad peaks in the background at low to moderate $2 \theta$ angles (amorphous humps; e.g., Achilles et al., 2013, Rampe et al., 2013, Warren, 1990). Because the peaks are broad and low, XRD patterns of amorphous materials are significantly less distinct than for crystalline phases. However, slight variations in peak positions can allow specific amorphous phases to be identified as possible candidates in the pattern of a multicomponent sample. This is generally done through a full-pattern fitting analysis, which involves using patterns of both crystalline and amorphous phases to fit the full diffraction pattern of a sample (Chipera \& Bish, 2013).

The Rocknest wind ripple sample from Gale Crater was comprised of loose, unconsolidated sediment (soil), and an analysis of CheMin data using the full-pattern fitting analysis software FULLPAT (Chipera \& Bish, $2002,2013)$ indicated that the Rocknest sample contained both crystalline and amorphous components (Achilles, Downs, Ming, et al., 2017; Bish et al., 2013). The crystalline component was consistent with a mafic igneous origin and consisted predominantly of plagioclase, forsterite, augite, and pigeonite. Bish et al. (2013) used patterns of a number of disordered materials (allophanes, ferrihydrite, aluminosilicate gels, and a synthetic basaltic glass of Gusev Crater composition) to model the amorphous component and found the best fit with basaltic glass and allophane patterns. However, the authors were careful to note that the amorphous component was not unambiguously identified by this analysis, because there could be many amorphous materials with similar XRD patterns. For example, they noted that allophane could be a surrogate for other phases, such as the ferric silicate hisingerite, which is favored given the low Al content of the amorphous component derived from mass balance calculations (Blake et al., 2013; Dehouck et al., 2014). The amorphous component of the Rocknest sample was also assumed to contain 1.5 to $3 \mathrm{wt} \% \mathrm{H}_{2} \mathrm{O}$ based off of lowtemperature $\mathrm{H}_{2} \mathrm{O}$ release measured by the Sample Analysis at Mars instrument (Leshin et al., 2013) and the fact that the crystalline components of the Rocknest sample were nominally anhydrous (Blake et al., 2013).

Abundance estimates for the amorphous component in the Rocknest sample have varied depending on the method of estimation. Bish et al. (2013) reported FULLPAT models from Rocknest scoops 4 and 5 containing 23 and 25 wt $\%$ Gusev composition basaltic glass, and 3 and 2 wt\% allophane-like material, summing to totals of 26 and $27 \mathrm{wt} \%$ amorphous component. When uncertainties ( $\pm 50 \%$ relative) were taken into consideration, the Rocknest sample contained an estimated range of 13 to $40.5 \mathrm{wt} \%$ amorphous abundance. After the Bish et al. (2013) investigation, it became apparent that the sample cells on the CheMin sample wheel were offset from their ideal diffraction position, and so a sample cell offset calibration method was developed (Morrison, Downs, Blake, Prabhu, et al., 2018, Morrison, Downs, Blake, Vaniman, et al., 2018). Achilles, Downs, Ming, et al. (2017) used this new method to revise the FULLPAT analyses of Rocknest data and determined that the amorphous component abundance was $35 \pm 15 \mathrm{wt} \%$ (for a range of 20 to $50 \mathrm{wt} \%$ ). MBCs (described in detail in section 3.5) using Rocknest CheMin mineralogy and bulk chemistry measurements from APXS presented varying results, but most fell within range of the abundances estimated by Bish et al. (2013): 36 wt $\%$ (Morris et al., 2013), 45 wt\% (Blake et al., 2013), and a minimum amorphous abundance of $22 \mathrm{wt} \%$ with values less than 25 wt\% considered unlikely (Dehouck et al., 2014).

The John Klein and Cumberland samples consisted of drill powder from the Sheepbed mudstone member of the Yellowknife Bay formation (Grotzinger et al., 2014). These samples were also found to contain both crystalline and amorphous components based on the XRD patterns (Vaniman et al., 2014). Rietveld refinements and FULLPAT analyses of CheMin data indicated that the crystalline component consisted predominantly of plagioclase, smectite, pigeonite, augite, orthopyroxene, magnetite, and sanidine (Vaniman et al., 2014), suggesting a mafic igneous provenance for the sediments (Grotzinger et al., 2014). Vaniman et al. (2014) calculated possible amorphous compositions using the bulk chemical compositions and the crystalline mineral compositions in a mass balance equation and found that the amorphous component was a Si-poor material enriched in $\mathrm{Fe}, \mathrm{S}, \mathrm{Cl}$, and $\mathrm{P}$. 
Vaniman et al. (2014) used FULLPAT and patterns of crystalline and amorphous phases to model amorphous abundances in the John Klein and Cumberland samples and found they contained 28 and $31 \mathrm{wt} \%$, respectively. The MBC was used to constrain the minimum abundance of amorphous material in the Cumberland sample to 15 or $18 \mathrm{wt} \%$ (depending on the composition of clay mineral used in the calculation) with proportions below 21 and 24 wt\% unlikely (Dehouck et al., 2014). CheMin has analyzed an additional 13 rock samples and two active eolian sediment samples to date. FULLPAT analyses and mass balance calculations of these samples suggest amorphous materials comprise anywhere from $15 \mathrm{wt} \%$ of the sample (i.e., Windjana, Treiman et al., 2016) to 73 wt\% of the sample (i.e., Lubango, Yen et al., 2017). MBC results suggest that the amorphous composition is highly variable, with some amorphous materials enriched in Si (e.g., Buckskin, Greenhorn, and Lubango; Morris et al., 2016; Yen et al., 2017), some enriched in Fe (e.g., Windjana and Marimba; Achilles, Downs, Rampe, et al., 2017; Treiman et al., 2016), and some enriched in $S$ (e.g., Confidence Hills, Mojave2, Marimba, and Sebina; Achilles, Downs, Rampe, et al., 2017; Rampe, Ming, et al., 2017).

\subsection{Standard XRD and Amorphous Analysis Techniques on Earth}

The mineral abundances of a strictly crystalline multicomponent sample can be derived from the measured XRD pattern using a number of quantitative X-ray diffraction analysis techniques. Most common are fullpattern fitting methods such as Rietveld refinement (e.g., Bish \& Howard, 1988, Rietveld, 1969) and FULLPAT analyses (Chipera \& Bish, 2002).

Rietveld refinement programs fit the shape of the background and then calculate a model using the crystal structures of the individual standard materials. A number of variables can be adjusted to improve the model during a Rietveld refinement such as sample offset, scale factors, unit cell parameters, peak widths, and preferred orientation (e.g., Bish \& Howard, 1988, Rietveld, 1969). Refining the lattice parameters allows for a more precise crystal chemistry to be calculated for solid solution phases (e.g., plagioclase and pyroxene; Morrison, Downs, Blake, Prabhu, et al., 2018). Once an acceptable model is produced, the phase weight percent abundances are calculated using the scale factors and densities of the crystalline phases.

The FULLPAT program uses a least squares minimization to optimize the fit between library patterns and a measured pattern, and the program allows for a restricted number of adjustments to the crystalline patterns in order to better fit the measured pattern (Chipera \& Bish, 2002). Once an acceptable model is produced, the crystalline phase weight percent abundances are normalized so that they sum to $100 \%$.

A number of additional steps must be taken during sample processing and data analysis to obtain accurate crystalline and amorphous abundances when a multicomponent sample contains X-ray amorphous materials. Commonly, the first step is to prepare the sample by adding a known abundance of a highly crystalline and pure internal standard (usually corundum). The mixture is measured, and the crystalline and amorphous abundances are estimated using a full-pattern fitting method.

The Rietveld refinement model for a crystalline and amorphous-bearing sample consists of: a background, individual crystalline phase patterns, and one or multiple broad peaks representing amorphous materials (but not necessarily corresponding to specific compositions) all of which are refined and scaled to match the measured pattern. The calculated internal standard mass fraction is compared to the actual internal standard mass fraction, and all crystalline diffraction data are scaled to produce the actual mass fraction, instead of scaling to $100 \%$ (e.g., Alexander \& Klug, 1948, Chung, 1974, Copeland \& Bragg, 1958, Hooton \& Giorgetta, 1977 , Klug \& Alexander, 1974). As a result, precise phase quantities of crystalline phases are obtained, and the difference from $100 \mathrm{wt} \%$ represents the abundance of amorphous materials.

The FULLPAT model for a crystalline and amorphous-bearing sample consists of a background, individual crystalline material patterns, and individual amorphous material patterns. The crystalline and amorphous material patterns are either measured or calculated so that they represent a mixture of the individual phase and internal standard at the same ratio added to the bulk sample (Chipera \& Bish, 2002). Each individual library pattern is scaled using the known abundance of internal standard, and a least squares minimization is used to optimize the fit between library patterns and a measured pattern (Chipera \& Bish, 2002). Once an acceptable model is produced, the crystalline and amorphous phase weight percent abundances are normalized so that they sum to $100 \%$. 
Adding an internal standard is not always desirable or possible because the sample becomes contaminated, and the additional sample preparation task is not feasible for an automated process. If no internal standard is included in the sample, amorphous component abundances estimated during full-pattern fitting remain dependent on a number of assumptions. For Rietveld refinements, an average material density must be assigned to the amorphous component, and then the weight percent abundance of the amorphous component is calculated by dividing the refined scale factors for the broad amorphous peaks by the assigned density (described in detail in section 3.6). However, since the composition and structure of the amorphous material is not known a prioi, we must make assumptions about its density, which could be a source of error in the estimated abundance.

For FULLPAT, a major requirement is that the XRD pattern for each individual phase/material, including the amorphous materials, has either been measured on a similar XRD instrument or been calculated using the same instrument parameters as the samples being analyzed. However, because few amorphous materials have been measured in general and because amorphous phases do not give definitive X-ray diffraction peaks, other amorphous materials absent from the FULLPAT library may also fit the measured data. Therefore, it is assumed that the selected amorphous standard pattern(s) are able to fully represent the amorphous component in the sample (Chipera \& Bish, 2002); if they do not, the amorphous abundances could be underestimated. Additionally, since the standard patterns are scaled to a known abundance of an internal standard, the substitution of one amorphous phase for another with a different scattering power could also cause an error in the estimated amorphous abundance

The MBC method is another method that can be used to determine the amorphous component abundance (Blake et al., 2013; Dehouck et al., 2014; Jones et al., 2000; Morris et al., 2013; Vaniman et al., 2014). This method requires bulk chemical analysis of the sample and uses a two-step process to (1) calculate the composition of the crystalline component of a sample using the mineral abundances determined through a fullpattern fitting analysis of XRD data and (2) calculate the possible amorphous component composition by subtracting the crystalline composition calculated in step (1) from the bulk sample composition (Blake et al., 2013; Dehouck et al., 2014; Morris et al., 2013; Vaniman et al., 2014). In this process, it is sometimes necessary to adjust the amorphous component abundance until nonnegative oxide weight percentages are obtained (discussed in section 3.6), and so the MBC method provides another amorphous component abundance estimate.

The internal standard, full-pattern fitting, and MBC methods utilize XRD data in different ways to quantify the amorphous component abundance in a sample. It is not certain how the abundances derived from each method compare for a single sample. Understanding potential differences is important to the interpretation of amorphous abundances measured in the laboratories here on Earth and on the Martian surface.

Amorphous materials in terrestrial samples, and especially in soils, are commonly estimated using selective dissolution methods, which are independent of XRD data (e.g., Borggaard, 1988, and references within). Oxalate extractable soil material is thought to contain most of the amorphous materials in soils (Jackson et al., 1986). In this method, samples are reacted with acid ammonium oxalate, and the difference in mass between the final and initial sample is considered the mass of the amorphous phases. Jones et al. (2000) performed the MBC technique on Hawaiian soil samples along with acid ammonium oxalate extractions. They concluded that the acid ammonium oxalate extractions only determine the chemically active portion of the amorphous fraction and that the $M B C$ technique should be used to determine the total amorphous content.

\subsection{XRD Analyses on Mars (CheMin Instrument)}

CheMin is a transmission XRD instrument with an energy-filtered cobalt (Co) X-ray source and an angular range of $5^{\circ}$ to $50^{\circ} 2 \theta$ with $<0.35^{\circ} 2 \theta$ angular resolution (Blake et al., 2012). The CheMin instrument is outfitted with a charge coupled device camer detector, which directly detects X-rays diffracted from the sample (Blake et al., 2012). The instrument has a detection limit of $\sim 1$ wt\% (Blake et al., 2012).

The CheMin XRD instrument was designed to accommodate a number of complications introduced by the limitations of conducting automated analyses on another planet. First, the nominal powder sample preparation procedure of grinding the sample while wet is too complex for the rover. Instead, the instrument accepts sieved $(<150 \mu \mathrm{m})$ drill powders and scooped samples but vibrates the sample cells throughout the 
measurements using piezoelectric actuators so that the sample exhibits bulk convective movement (Blake et al., 2012). Doing so ensures that grains are measured in random orientation over time.

It is not practical to prepare samples for quantitative analysis with an internal standard onboard the rover; this process in terrestrial laboratories involves weighing known quantities of both sample and the standard and then powdering them together to create a mixture of uniform particle size. Instead, CheMin data are analyzed with full-pattern fitting methods that employ a library of mineral and amorphous material patterns. The individual patterns are most often calculated from crystal structures using the proper CheMin instrument and profile parameters but can also be measured on the CheMin test bed instruments (Blake et al., 2012).

\subsection{Chemical Measurements on Mars-APXS Instrument}

The APXS instrument on the MSL rover is capable of determining the chemical composition of rocks and soils by X-ray spectroscopy. APXS combines the terrestrial standard methods of particle-induced X-ray emission and X-ray fluorescence in order to measure major and trace elements from sodium to bromine (Gellert et al., 2015). APXS has a spot size of $1.7 \mathrm{~cm}$ in diameter when the instrument is in contact with the sample and averages over all mineral grains in its field of view (Gellert et al., 2015). It should be noted that APXS measures a different sample than CheMin; sieved samples are delivered to CheMin directly from a drill hole or sample scoop, while APXS measures sieved fines that are dumped on the ground.

\section{Methods}

\subsection{Samples and Processing Techniques for Bulk Measurements}

Three samples from different Mars-like terrestrial settings were chosen for this study: mafic glacial sediment from the Three Sisters volcanoes in Oregon (Scudder et al., 2016), a basaltic soil from the Big Island of Hawaii (Chadwick et al., 1999), and a paleosol developed on intermediate composition pyroclastics from the John Day Fossil Beds National Monument in Oregon (Retallack et al., 1999). These specific samples were selected because they come from environments known or hypothesized to contain significant amorphous materials. Ongoing work shows that subglacial and periglacial weathering of glacial flour produces amorphous materials, which have been identified in glacial sediments (Scudder et al., 2017; Rampe, Horgan, et al., 2017). The Hawaiian soil comes from a region on Hawaii where the weathering is dominated by infrequent monsoons, and this rapid weathering has been shown to drive the preferential production of allophanic phases over crystalline weathering products (Ziegler et al., 2003). The paleosol is from a portion of the Blue Basin member in the John Day Fossil Beds that has undergone minimal diagenesis since burial. This sample is hypothesized to be a fairly young glass-rich pyroclastic soil from a cooler and more arid climate, and both the high glass content and cool climate are thought to enhance the production of amorphous phases during soil formation (Horgan et al., 2017).

Soil and sediment samples were dried under a fume hood then sieved to $<150-\mu \mathrm{m}$ size fraction, because that is the size fraction analyzed by the CheMin instrument. The $<150-\mu \mathrm{m}$ size fraction material will be referred to as bulk sample in order to distinguish between these and the $<2-\mu \mathrm{m}$ size fraction materials discussed below. The paleosol sample was broken down into pebble and sand-sized particulate using a rock hammer.

Powders were prepared with internal standards (spiked) by adding $20 \mathrm{wt} \%$ corundum $\left(\mathrm{Al}_{2} \mathrm{O}_{3}\right)$ to the sieved or particulate sample and then powdering the mixture under ethanol using a McCrone micronizing mill for $10 \mathrm{~min}$ to achieve a particle size of $\sim 25 \mu \mathrm{m}$. Powders without an internal standard (not spiked) were processed using the same methods as above, but the corundum was omitted.

\subsection{Sample Processing for Oriented Clay Measurements}

Samples were prepared for XRD oriented clay mounts using the following methods pioneered by Moore and Reynolds (1997): $\sim \mathrm{g}$ of sample was placed in $250 \mathrm{ml}$ beakers and the beakers were filled with deionized water. The sample/water mixture was sonicated for $5 \mathrm{~min}$, and the resulting liquid suspension was decanted into centrifuge tubes. The liquid was centrifuged at 1,000 rotations per minute for 50 seconds (such that the $<2-\mu \mathrm{m}$ particles were left in suspension), after which the supernatant fluid was decanted into Nalgene bottles. A dropper was used to aliquot some of the supernatant fluid onto a zero background slide. The slides were placed in an oven heated to $50^{\circ} \mathrm{C}$ until the liquid was evaporated. The clay mounts were then spritzed with a $10 \%$ glycerol solution, a molecule that, when solved, will extend the swelling phyllosilicate interlayers 
to d-spacings specific for each phyllosilicate structure, and were allowed to dry. The oriented clay mounts were measured twice, once after the first drying and once again after the glycerol treatment.

\subsection{X-ray Diffractometer}

\subsubsection{Laboratory XRD}

All bulk powdered and oriented clay samples were measured using a PANalytical X'pert Pro MPD XRD at either Johnson Space Center or at the Center for Agronomy Science at Purdue University; both instruments are equipped with $X^{\prime}$ Celerator detectors. XRD patterns were collected under the following conditions: Co Ka $\mathrm{X}$-ray source, a Fe filter to reduce $\mathrm{K} \beta$ peak intensities, $45 \mathrm{kV}, 40 \mathrm{~mA}, 1 / 2^{\circ}$ antiscatter slit, $1 / 4^{\circ}$ fixed divergence slit, and a beam knife to reduce low-angle scattering. Samples were measured from $2^{\circ}$ to $80^{\circ} 2 \theta$ with a $0.01067^{\circ}$ step size and $100 \mathrm{~s} / \mathrm{step}$. The powdered samples were dispersed into back-loaded sample mounts for XRD analysis.

\subsubsection{CheMin IV}

The three bulk samples (not spiked) were measured using the CheMin IV test bed instrument located at Johnson Space Center. The glacial and Hawaiian samples measured on the CheMin IV were sieved, not powdered, akin to loose sediment samples collected by the MSL rover, while the paleosol rock sample was powdered and is analogous to a drill-tailing sample delivered to the MSL rover. All samples were measured in Mylar cells. The CheMin IV utilizes a microfocus energy-filtered Co K $\alpha$ X-ray source to construct the patterns, which removes X-ray fluorescence from the sample. CheMin IV also utilizes a transmission sample cell that is piezoelectrically shaken during analysis in order to maintain a randomly oriented sample. The patterns were collected from $4^{\circ}$ to $56^{\circ} 2 \theta$ with a $<\sim 0.35^{\circ}$ step size, collecting five hundred 30 -s exposures at $30 \mathrm{kV}$ and $0.30 \mathrm{~mA}$.

\subsubsection{Full-Pattern Fitting Data Analyses: Rietveld Refinements and FULLPAT}

For this study, Rietveld refinements of XRD patterns were performed using the Materials Data, Inc. (MDI) Jade analytical software. The backgrounds were fitted with a first-order polynomial curve, crystalline phases were modeled using a Pearson-VII (exponent/Lorentzian) peak shape function, and amorphous peak profiles were modeled using a pseudo-Voigt function. For patterns measured on the PANalytical, fits were performed between $5^{\circ}$ and $80^{\circ} 2 \theta$ for the glacial sediment and Hawaiian soil samples and from $10^{\circ}$ and $80^{\circ} 2 \theta$ (excluding the regions $22.3^{\circ}-23.9^{\circ}$ and $40^{\circ}-40.8^{\circ} 2 \theta$ ) for the paleosol to exclude the largest smectite peaks from the refinement. Fits were performed between $5^{\circ}$ and $55^{\circ} 2 \theta$ for all samples measured on the CheMin IV. The scale factors, unit cell parameters, peak width, and shape for each mineral phase were allowed to vary for refinements of both PANalytical and CheMin IV patterns. The skewness/asymmetry of mineral peaks was allowed to vary in refinements of PANalytical patterns, but not CheMin IV patterns because the transmission geometry in CheMin IV results in symmetrical peaks. Specimen displacement was refined for patterns measured on the PANalytical, but not the CheMin IV, because the fixed position of the sample in the CheMin IV prevents sample displacement. Atomic positions and occupancies and temperature factors were not refined for patterns measured on either instrument. The peak position, height, full width at half maximum, and peak shape were allowed to vary for the amorphous hump(s) in both PANalytical and CheMin IV patterns.

For the not spiked samples, the amorphous abundance is calculated in Jade essentially by dividing the modeled amorphous peak scale factors by the density of the amorphous material. Since the density of the amorphous material is not known a priori, one had to be assigned to the amorphous component. Rietveld refinements of the not spiked patterns were run twice, each time using a different assigned density for the amorphous materials: (1) a calculated density and (2) a default or nominal density. The calculated amorphous material densities were derived from the Rietveld refinement of the spiked samples. During the refinement, the Jade software calculates the amorphous material density by adjusting the density value until the resulting amorphous abundance (scale factor divided by density) is equal to the amorphous abundance calculated as the difference from 100\% (100-sum of crystalline components). The default or nominal density in Jade, $2.5 \mathrm{~g} / \mathrm{cm}^{3}$, is close to an average density for silicate materials (e.g., opal $\sim 2.0 \mathrm{~g} / \mathrm{cm}^{3}$, basaltic glass $\sim 3.0 \mathrm{~g} /$ $\mathrm{cm}^{3}$ ) and would be comparable to that of an amorphous silicate with an intermediate (approximately andesitic) composition. These two density values were tested in order to determine the effect of density on the amorphous abundance and composition estimates. This is important for instances when it is not practical to add an internal standard to the sample, as is the case for Martian samples. In this case, an amorphous material density cannot be calculated. 
Because the TC-1 paleosol sample contains smectitic clay minerals, which tend to have complex and variable crystal structures and compositions, the Rietveld refinement methods differ slightly from those of the other two samples. Two different modeling methods were used in the refinements for each TC- 1 sample preparation/measurement style: (1) excluding all clay peaks so that clay and amorphous materials are grouped together by modeling the pattern from $10^{\circ}$ to $80^{\circ} 2 \theta$ (excludes the 001 peak) and ignoring the range between $22.3^{\circ}$ and $23.9^{\circ} 2 \theta$ (excludes the 021 peak) and (2) modeling clay abundances separately from amorphous by using individual smectite patterns as an overlay and assuming a reference intensity ratio of 1 . Because reference intensity ratios can be challenging to calculate for clay minerals, the results from the second method are tenuous and are only shown in the supporting information for completion.

Plagioclase, pyroxene, and olivine mineral formulae were estimated by comparing the refined unit cell parameters to those in Morrison, Downs, Blake, Prabhu, et al. (2018; Table S3). These methods assume compositions of $\mathrm{Na}-\mathrm{Ca}$ for plagioclase, $\mathrm{Mg}-\mathrm{Fe}-\mathrm{Ca}$ for pyroxene, and $\mathrm{Mg}$-Fe for olivine and do not include other elements that might substitute in the crystal structure in minor abundances.

CheMin IV XRD data were also analyzed using a modified version of the FULLPAT program (Chipera \& Bish, 2002). This version of FULLPAT is used by the CheMin team to determine the abundance of X-ray amorphous phases in CheMin patterns (Bish et al., 2013; Morris et al., 2016; Rampe, Ming, et al., 2017; Treiman et al., 2016; Vaniman et al., 2014; Yen et al., 2017). Patterns were fit from $5^{\circ}$ to $55^{\circ} 2 \theta$ with a library including a variety of $X-$ ray amorphous phases (basaltic glass, rhyolitic glass, ferrihydrite, allophane, and Al-Si gel), phyllosilicates, crystalline minerals previously identified using Jade, and Mylar cell window and linear backgrounds.

\subsection{Bulk Chemistry}

Bulk samples (sieved to $<150 \mu \mathrm{m}$ for glacial sediment and Hawaiian soil samples) were sent to ActLabs for chemical analysis. This analysis included $\mathrm{X}$-ray fluorescence measurements of bulk samples to determine $\mathrm{Al}_{2} \mathrm{O}_{3}, \mathrm{CaO}, \mathrm{Cr}_{2} \mathrm{O}_{3}, \mathrm{Fe}_{2} \mathrm{O}_{3}$ (Fe Total), $\mathrm{K}_{2} \mathrm{O}, \mathrm{MgO}, \mathrm{MnO}, \mathrm{Na}_{2} \mathrm{O}, \mathrm{P}_{2} \mathrm{O}_{5}, \mathrm{SiO}_{2}$, and $\mathrm{TiO}_{2}$ abundances; infrared radiation to measure $\mathrm{SO}_{3}{ }^{2-}$; and instrumental neutron activation analysis to measure $\mathrm{Cl}^{-}$. FeO was also measured using titration, and $\mathrm{Fe}_{2} \mathrm{O}_{3}$ was calculated as the difference between $\mathrm{Fe}_{2} \mathrm{O}_{3}$ (Fe Total) and $\mathrm{FeO}$.

\subsection{Mass Balance Calculation}

The mass balance calculation used to estimate the abundance and composition of the amorphous component in a sample is a two-step process: (1) calculate the compositions of the crystalline components using the mineral abundances and unit cell parameters to constrain crystal chemistry (Morrison, Downs, Blake, Prabhu, et al., 2018, Morrison, Downs, Blake, Vaniman, et al., 2018) and (2) calculate the most likely amorphous component composition by subtracting the crystalline component composition from the bulk sample composition measured during chemical analysis. The calculations were performed using a Scilab 5.4.1 (Scilab Enterprises, 2014) program developed by Dehouck et al. (2014) specifically for mass balance calculations applied to Mars data. The two steps are summarized by the following equations:

$$
\begin{gathered}
y_{\text {cryst }}=\Sigma_{i}\left(y_{i}\right)\left(x_{i}\right) ; \text { with } \sum_{i} x_{i}=100 \\
y_{\text {amoph }}=\frac{y_{\text {bulk }}-y_{\text {cryst }}}{x_{\text {amorph }}}+y_{\text {cryst }}
\end{gathered}
$$

where y represents the abundance in weight percent of a given oxide in a given mineral $\left(y_{i}\right)$, the bulk sample $\left(y_{\text {bulk }}\right)$, the crystalline component $\left(y_{\text {crst }}\right)$, or the amorphous component $\left(y_{\text {amorph }}\right) ; x_{i}$ represents the amorphous-free abundances of crystalline phases; and $x_{\text {amorph }}$ is the proportion of amorphous component (a free parameter as discussed below; Dehouck et al., 2014). The chemical compositions of the primary and secondary minerals used in the calculations can be found in supporting information Table S1. APXS does not measure the lightest elements, and so all mineral compositions used in the calculations are volatile $\left(\mathrm{H}_{2} \mathrm{O}\right.$ and $\left.\mathrm{CO}_{2}\right)$ and $\mathrm{OH}^{-}$free and normalized to $100 \%$. The SciLab program also considers three different abundances for each mineral: the best estimate, the maximum (the best estimate plus the associated uncertainty), and the minimum (the best estimate minus the associated uncertainty; Dehouck et al., 2014).

When the MBC is applied to clay-bearing Martian samples, clay minerals are frequently grouped with the amorphous component due to the difficulty of accurately quantifying and identifying clay minerals without a number of additional laboratory procedures (e.g., Rampe, Ming, et al., 2017). In order to be consistent with 
CheMin results, we similarly grouped clay minerals into the amorphous component for the clay-bearing sample in this study (TC-1).

It is likely that the amorphous component of the terrestrial samples contains some volatiles. However, it is uncertain how much of the loss on ignition component measured during elemental abundance measurements can be attributed to the amorphous component. Therefore, we chose to subtract the loss on ignition component of each sample and normalize all bulk elemental data to $100 \%$. Doing so does not affect the relative weight percent oxide composition of the amorphous component but does affect the absolute composition.

It is important to note a few limitations of the MBC method. First, the composition of crystalline phases that are below the detection limit of XRD will, by default, be allocated to the amorphous component composition. Second, crystalline minerals frequently contain minor elemental substitutions not reported in their ideal structure formula. These compositions are not reflected in the XRD models, and so they are also allocated to the amorphous component composition. Lastly, the composition of the amorphous component is a bulk composition that very likely represents an unknown number of distinct and/or compositionally variable amorphous phases present in each sample, rather than a single amorphous phase.

\subsection{Amorphous Abundance}

Amorphous abundances were estimated in four ways for each sample: (1) calculated as the difference between $100 \%$ and the total crystalline material weight percent-the internal standard method, (2) modeled in the Rietveld refinement of the XRD data using Jade, (3) modeled in the FULLPAT analysis of the CheMin IV XRD data, and (4) adjusted as a free parameter in the MBC. Amorphous abundances were calculated from XRD data of samples containing a known amount of internal standard ( $20 \mathrm{wt} \%$ corundum) by first estimating crystalline component abundances using the Rietveld refinement analysis option in Jade. A scale factor was calculated by dividing the actual internal standard mass fraction by the modeled internal standard mass fraction, and the calculated scale factor was then applied to all of the components in the model to produce the actual mass fractions of the crystalline components. The amorphous component abundance is assumed to account for the difference between $100 \%$ and the total weight percent of the crystalline components. Of all the amorphous abundance estimation methods employed in this study, the internal standard method requires the fewest assumptions and is therefore considered the most accurate estimate.

For the Rietveld refinements of the not spiked samples using Jade, the abundance of the amorphous component is calculated by dividing the refined scale factors for the amorphous peaks by the assigned density of the amorphous component. Since the Rietveld refinement process uses only broad peaks to represent amorphous scattering, a density (or composition) must be assigned to the amorphous material. As stated above in section 3.3.3, we used both a nominal density of $2.5 \mathrm{~g} / \mathrm{cm}^{3}$ and a density calculated using the spiked sample.

For the FULLPAT analyses, the amorphous component is modeled with patterns of specific amorphous materials, and the abundance of the amorphous component is the sum of the weight percent for each individual amorphous material used in the model.

The MBC method assumes that the full-pattern fitting methods provide only relative abundances for crystalline phases, which allows the abundance of amorphous components to be an input parameter. Initially, we input the amorphous abundance estimated from the full-pattern fitting method and then adjusted the abundance until we reached the lowest percentage of amorphous material needed to ensure nonnegative weight percent oxide solutions for the amorphous component composition (Dehouck et al., 2014). In this way, this method was used to constrain the lower limit for the abundance of amorphous material present. Therefore, the abundances derived from the two approaches are not necessarily expected to match perfectly; nonetheless, the abundance derived from the MBC should always be less than or equal to the value derived from the full-pattern fitting methods.

\section{Results}

\subsection{Bulk Sample Mineralogy}

XRD patterns and associated Rietveld refinement fits of the three terrestrial samples are shown in Figure 1. Crystalline mineral abundances modeled using full-pattern fitting of XRD patterns of all spiked and not 

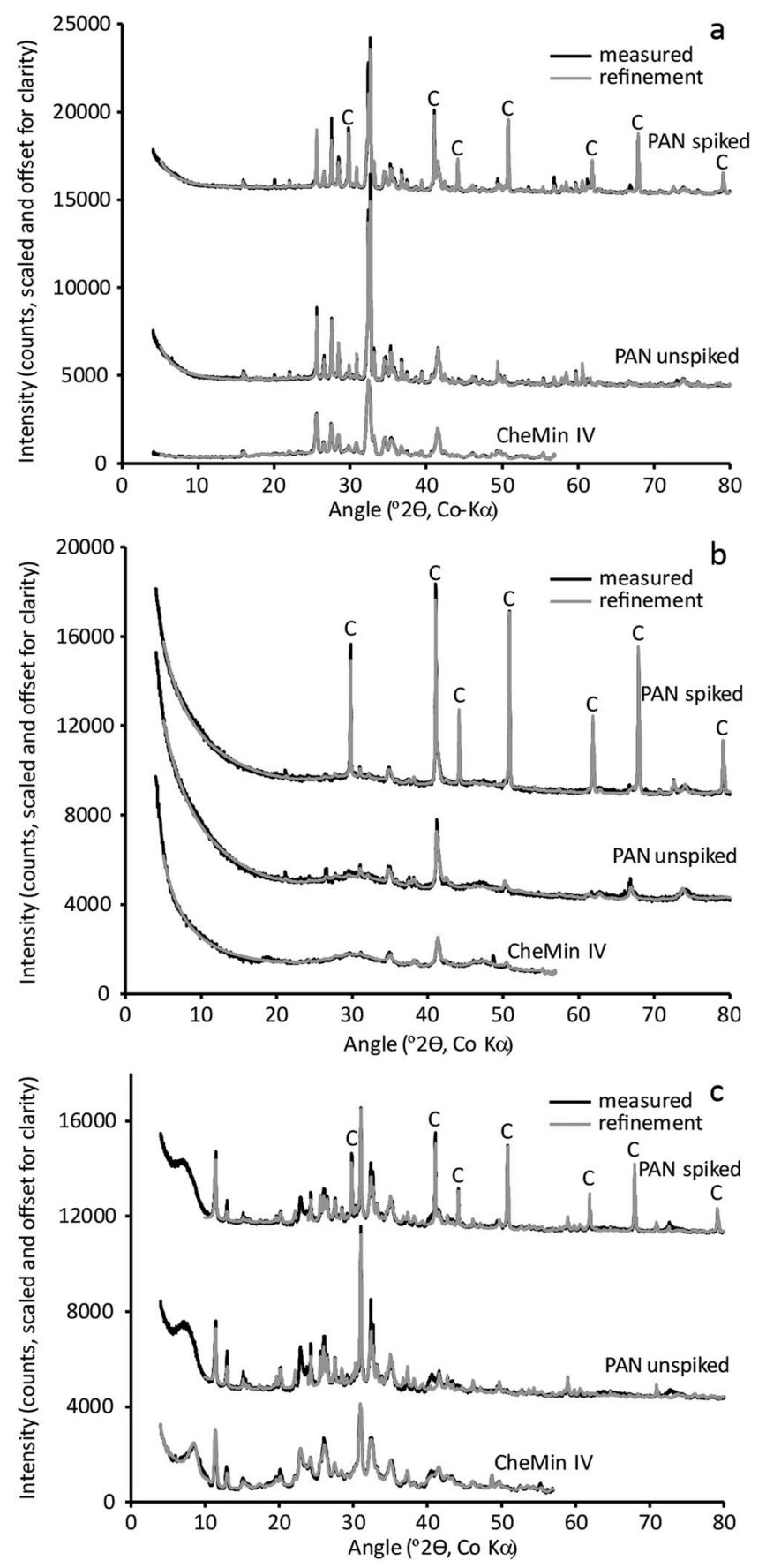

Figure 1. Measured XRD patterns (black) with corresponding Rietveld models (gray) for 160814X (a), 2-Laupahoehoe (b), TC-1 (c). Plots compare patterns for samples measured on the PANalytical instrument with and without an internal standard (PAN spiked and PAN unspiked, respectively) and on the CheMin IV instrument without an internal standard (CheMin IV). Corundum (internal standard) peaks are labeled $C$. spiked bulk samples are shown in Figure 2 (values can be found in Table S4). The refined unit cell parameters can be found in supporting information Table S2, and the crystal chemistry for the refined minerals can be found in supporting information Table S3. Because of sample heterogeneity, each spiked and not spiked sample was measured a number of times in order to obtain patterns similar to each other. As a result, the modeled assemblages for each sample are relatively consistent across measurements, including with or without an internal standard and measured using the PANalytical versus CheMin IV instruments. The variations in mineral abundances between measurements are consistent with minor heterogeneity in the samples (Figure 2). This suggests that in most cases, the presence or lack of an internal standard should not drastically affect the relative crystalline mineralogy of a sample.

The glacial moraine sediment sample (160814X) mineralogy consists primarily of plagioclase, pyroxene, and olivine, with small abundances of hematite ( 2 wt\%) and magnetite ( 1 wt\%; Figure 2$)$. Thus, this sample appears to be volcanic sediment with minimal additional crystalline alteration phases. The largest discrepancies in mineralogy between the different $160814 \mathrm{X}$ patterns are in the modeled abundances of feldspar (standard deviation of 4.5) and pyroxene (standard deviation of 1.2).

The Hawaiian soil sample (2-Laupahoehoe) mineralogy is dominated by magnetite, olivine, and pyroxene (Figure 2). Similar high abundances of magnetite have been documented in other Hawaiian soil samples (Van Dam et al., 2008). The two most apparent discrepancies in mineralogy between 2-Laupahoehoe PANalytical patterns is that pyroxene is modeled in abundance $\sim 10 \%$ higher in the spiked sample than all other samples.

The paleosol sample (TC-1) mineralogy is dominated by plagioclase, zeolite, and quartz (Figure 2), and clay minerals are estimated at $\sim 38 \mathrm{wt} \%$ using FULLPAT (Table S4). Thus, the sample is consistent with a highly weathered volcanic parent lithology. The paleosol (TC-1) was the only sample with XRD evidence for clay minerals, so this was the only sample for which an oriented clay mount was prepared. In the bulk patterns for TC1, the phyllosilicate 001 peak is located at $12.5 \AA$ for the not spiked sample and $15 \AA$ for the spiked sample (Figure S1). This difference in position likely represents differences in hydration states of the clay in each sample, potentially due to different environmental conditions (e.g., relative humidity) during measurement. When fully hydrated using the glycerol treatment, the oriented clay mount pattern has a 001 peak positioned at $18 \AA$, consistent with smectite (Figure S1). There is also a shoulder positioned at $10 \AA$ that is likely associated with mica or illite. The smectite can be further distinguished by the position of the 06 l peak. For TC-1, this is located at $1.507 \AA$, which is more consistent with montmorillonite 061 peak positions $(\sim 1.492-1.504 \AA)$ than nontronite 06 l peak positions $(\sim 1.521 \AA$ ) or saponite 06 l peak positions $(\sim 1.53-1.54 \AA)$, but this slightly shifted peak may suggest some Fe substitution in the Al-smectite (Moore \& Reynolds, 1997). These interpretations are consistent with evolved gas analysis for this sample (Figure S2).

\subsection{CheMin IV Mineralogy}

As shown in Figure 2, the mineralogy derived from the full-pattern fitting of data collected on the CheMin IV instrument is similar to the mineralogy derived from the refinement of data collected on the PANalytical XRD. The FULLPAT results for TC- 1 shown in Figure 2 exclude clay abundances in order to be comparable to Rietveld refinement results. Slight variations in mineral abundances between measurements are consistent 


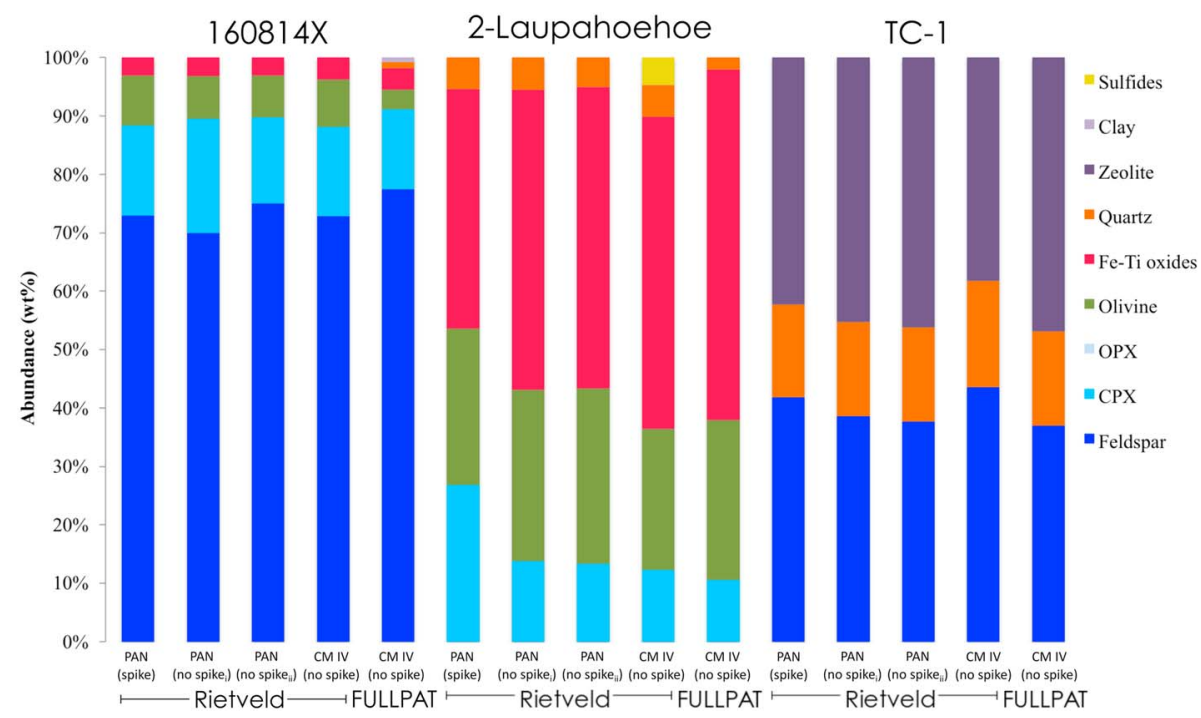

Figure 2. Best estimate mineralogy from Rietveld refinements of quantitative (spike) and non-quantitative (no spike) glacial sediments (160814X), Hawaiian soil (2-Laupahoehoe), and mafic paleosol (TC-1) measured on the PANalytical and CheMin IV instruments. Also shown in comparison is mineralogy derived using FULLPAT analytical techniques for CheMin IV data. TC-1 CheMin IV analyses shown here are normalized to $100 \%$ after subtracting clay abundances. (i) The Rietveld refinement was performed using the nominal density, and (ii) the refinement was performed using the calculated density. Individual minerals have been grouped for clarity. See supporting information for full mineral details.

with minor heterogeneity in the samples (values can be found in Table S4). Two major exceptions are the presence of pyrite modeled in the CheMin IV data for the 2-Laupahoehoe sample but not in the PANalytical data, and the quartz and clay mineral abundances modeled in the CheMin IV data for the 160814 X sample. Pyrite is used to model small peaks at $2.7,2.4$, and $2.2 \AA$ in the CheMin IV data for sample 2-Laupahoehoe. The same small peaks are visible in the PANalytical data but were modeled using ilmenite in the refinement, along with a peak at $\sim 64^{\circ} 2 \theta$ (CoK $\alpha$ ), which is beyond the range of the CheMin IV instrument. Therefore, it is more likely that pyrite is substituting for ilmenite in the FULLPAT analysis of this sample. Quartz and clay are modeled at very low abundances in $160814 \mathrm{X}(0.1$ and $0.5 \mathrm{wt} \%$, respectively; Table S4) and could represent heterogeneity in the sample.

\subsection{Amorphous Component Abundance}

Amorphous component abundances for each sample based on full-pattern fitting and best case MBCs (i.e., the minimum amorphous abundance calculated without mineral abundance uncertainties) are shown in Figure 3. In general, the abundances derived from full-pattern fitting (both Rietveld refinements and FULLPAT) of not spiked data (solid bars, Figure 3) are close to those derived using the internal standard method (solid gold bars, Figure 3). For nonclay-bearing samples (160814X and 2-Laupahoehoe), the minimum amorphous abundances estimated using MBCs (hatched gold bars in Figure 3) are almost always lower than those estimated with the Rietveld refinements (solid gold bars in Figure 3). This is because the Rietveld refinement amorphous abundances produce chemically realistic amorphous compositions so that the amorphous abundances must be lowered in order to obtain an unrealistic amorphous composition. Chemically realistic here means that when scaled with the amorphous abundance, the chemical composition of the bulk crystalline component modeled from the Rietveld refinement does not predict any oxide in the amorphous component at an abundance that is less than zero. So in this case, the minimum amorphous abundance values from the mass balance method are the least abundance of amorphous component that will still allow for a chemically realistic amorphous composition. This indicates that the MBC method can readily be applied to nonclay-bearing samples.

For the clay-bearing paleosol sample (TC-1), the values shown in Figure 3 are combined amorphous + clay abundances. This is the only sample in our set where the amorphous (+clay) estimate from the Rietveld refinement of spiked data (solid gold bars, Figure 3 ) does not produce a chemically realistic composition 


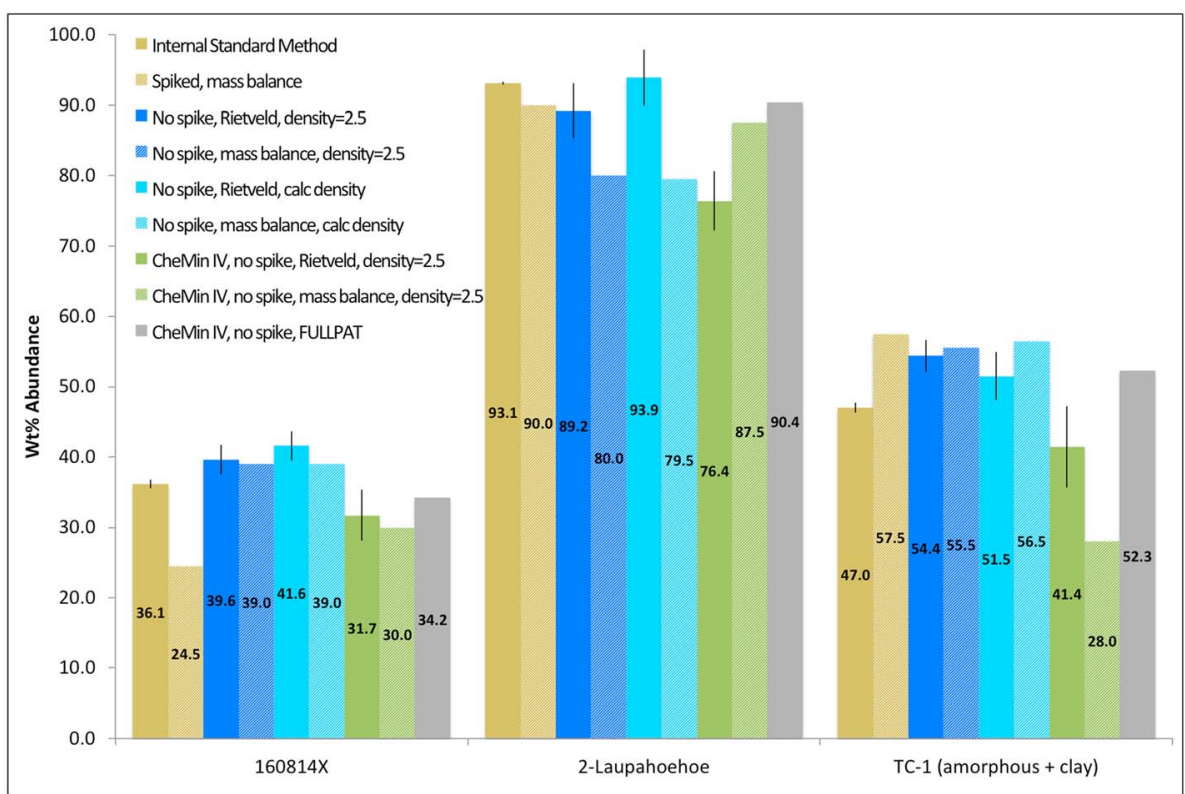

Figure 3. Abundance of amorphous materials calculated using the internal standard method compared to estimates modeled using Rietveld refinements (best estimate mineralogy), mass balance calculations, and FULLPAT analyses for the glacial sediments (160814X), Hawaiian soil (2-Laupahoehoe), and mafic paleosol (TC-1). Rietveld models were calculated for patterns of samples with (spiked) and without (no spike) internal standards on a PANalytical instrument. No spike samples were also measured on the CheMin IV test bed instrument. Error bars on Rietveld-derived abundances represent percent uncertainties in the models.

when used as an input for the MBC. In fact, for almost all of the TC-1 samples, the amorphous abundance estimates from the MBCs (hatched bars, Figure 3) are higher than the estimates from the Rietveld refinements (solid bars, Figure 3), indicating inaccuracies with the Rietveld refinement models. The only exception for this sample is the Rietveld refinement amorphous + clay estimate from the CheMin IV data, which does produce a chemically realistic amorphous component. Therefore, the MBC must be used carefully when a sample contains clay minerals.

Taking all estimation methods and measurement techniques into account, the glacial sediment sample (160814X) has an average estimated abundance of amorphous component of $\sim 35 \mathrm{wt} \%$ with a standard deviation of 5.5. As stated above, all minimum abundances from the MBC method (Figure 3, hatched bars) are less than those derived from the refinements (Figure 3, solid bars), and the oxide that determines the minimum abundance of amorphous component (the limiting oxide) in all cases is $\mathrm{CaO}$. The amorphous abundances derived from the Rietveld refinements of not spiked PANalytical data are slightly overestimated compared to the internal standard method, regardless of assigned amorphous material density (nominal and calculated; 2.5 and $2.3 \mathrm{~g} / \mathrm{cm}^{3}$, respectively). When measured on the CheMin IV instrument without an internal standard, the amorphous abundance from the Rietveld refinement (31.7 wt $\%)$ is slightly less than values derived from the refinements of samples measured on the PANalytical instrument (36.1, 39.6, and $41.6 \mathrm{wt} \%)$. The amorphous abundance derived from the FULLPAT analysis of CheMin IV data (34.2 wt\%) is very similar to that derived from the refinement of spiked XRD data (36.1 wt $\%$ ).

The Hawaiian soil sample (2-Laupahoehoe) has the highest average amorphous abundance across all estimation methods and measurement techniques estimated at $86.7 \mathrm{wt} \%$ with a standard deviation of 6.4 . For all 2-Laupahoehoe samples measured on the PANalytical instrument, the minimum abundances from the MBC method (Figure 3, hatched bars) are less than those derived from the refinements (Figure 3, solid bars), and the oxide that determines the minimum abundance of amorphous component (the limiting oxide) for all PANalytical data is $\mathrm{CaO}$. When measured without an internal standard on the CheMin IV instrument, the amorphous component abundance from the refinement model $(76.4 \mathrm{wt} \%)$ is significantly less than that derived from the internal standard method (93.1 wt\%) and must be increased to $87.5 \mathrm{wt} \%$ in order to obtain a chemically realistic result using the $\mathrm{MBC}$ method, with $\mathrm{SO}_{3}$ as the limiting oxide. In this case, 
the amorphous component is used to dilute the sample by increasing the amorphous abundance until potentially negative $\mathrm{SO}_{3}$ abundances in the amorphous component are forced to zero abundance. For not spiked 2-Laupahoehoe samples measured on the PANalytical, the amorphous abundance is underestimated when calculated using the nominal density $\left(2.5 \mathrm{~g} / \mathrm{cm}^{3}\right)$ and slightly overestimated when calculated using the calculated density $\left(1.34 \mathrm{~g} / \mathrm{cm}^{3}\right)$. The amorphous abundance derived from the FULLPAT analysis of CheMin IV data (90.4 wt\%) is very similar to that derived from the refinement of spiked XRD data (93.1 wt\%).

Taking all estimation methods and measurement techniques into account, the paleosol sample (TC-1) has an average estimated abundance of amorphous + clay component of $\sim 51 \mathrm{wt} \%$ with a standard deviation of 9.2 (Figure 3). The limiting oxide in all MBCs using PANalytical data is $\mathrm{CaO}$, whereas the limiting oxide for the sample measured on the CheMin IV instrument is $\mathrm{Na}_{2} \mathrm{O}$. When the calculated amorphous density is used in the refinements, the amorphous + clay abundance for the not spiked TC- 1 sample (51.5 wt $\%)$ is close to that derived from the spiked sample ( $47 \mathrm{wt} \%$ ). When using the nominal density, the estimated amorphous + clay abundance ( $54.4 \mathrm{wt} \%$ ) is slightly overestimated when compared to the abundance from the internal standard method (47 wt\%). The FULLPAT analysis of TC-1 measured on the CheMin IV instrument without an internal standard estimates an amorphous + clay abundance of $52.3 \mathrm{wt} \%$, which is consistent with results from the other estimation methods.

\subsection{Amorphous Component Composition}

Calculated compositions for the crystalline and amorphous portions of all samples are shown in Figure 4. These compositions were calculated using the best case mineral abundances (i.e., assuming no mineral abundance uncertainties) and the unit cell parameter derived plagioclase, pyroxene, and olivine compositions found in supporting information Table S3. The proportion of amorphous component $\left(x_{\text {amorph }}\right)$ used for the MBC is either the value from the Rietveld refinement (if it produces a chemically realistic composition) or the minimum abundance needed for a chemically realistic result (see Table S5 for values used).

Regardless of sample preparation method (internal standard or not) and instrument (PANalytical or CheMin IV), the amorphous components have relatively similar $\mathrm{SiO}_{2}, \mathrm{Al}_{2} \mathrm{O}_{3}, \mathrm{Fe}_{\mathrm{Total}}$, and $\mathrm{TiO}_{2}$ abundances within each sample (values found in Table $\mathrm{S} 6$ ). $\mathrm{K}_{2} \mathrm{O}, \mathrm{Na}_{2} \mathrm{O}, \mathrm{CaO}$, and $\mathrm{MgO}$ abundances are much more variable. Results regarding minor oxides/elements $\left(\mathrm{Cr}_{2} \mathrm{O}_{3}, \mathrm{MnO}, \mathrm{P}_{2} \mathrm{O}_{5}, \mathrm{SO}_{3}\right.$, and $\left.\mathrm{Cl}^{-}\right)$should be taken with care: these oxides are absent from the mineral compositions used for the $\mathrm{MBC}$ method (Table $\mathrm{S} 1$ ), so they are systematically included in the amorphous component. Since they represent only a small proportion of the bulk $(\sim 0.5,1.5$ and $0.3 \mathrm{wt} \%$, respectively), they do not significantly influence the minimum abundances given above. In general, these results show that the composition of the amorphous component derived from CheMin data is generally comparable to that calculated from a traditional quantitative XRD analysis.

For the glacial sediment sample, mass balance calculations yield similar amorphous component compositions regardless of sample preparation or instrumentation (160814X; Figure 4a). The most notable difference is in the compositions of the sample measured with an internal standard on the PANalytical instrument, for which the calculated amorphous component composition has slightly more $\mathrm{CaO}$ than the other two methods (Figure 4a). This is due to a lower abundance of Ca-augite and Ca-feldspar modeled in the refinement for the sample with an internal standard (Table S4). All of the $\mathrm{TiO}_{2}, \mathrm{Cr}_{2} \mathrm{O}_{3}, \mathrm{MnO}, \mathrm{K}_{2} \mathrm{O}, \mathrm{P}_{2} \mathrm{O}_{5}, \mathrm{SO}_{3}$, and Cl are calculated to reside in the amorphous component. Additionally, the amorphous component has slightly elevated $\mathrm{SiO}_{2}$ and $\mathrm{Fe}_{\text {Total }}$ abundances when compared to the crystalline component. Using FULLPAT, the majority of the amorphous material is modeled with basaltic glass (33.4 wt\%) with very low abundances of ferrihydrite (0.8 wt\%, Table S4).

For the Hawaiian soil sample, mass balance calculations yield very similar amorphous component compositions regardless of sample preparation or instrumentation (2-Laupahoehoe; Figure 4b). The amorphous component of the Hawaiian soil sample (2-Laupahoehoe) has the highest $\mathrm{Al}_{2} \mathrm{O}_{3}$ abundance out of all the samples regardless of the dataset used to derive the composition (Figure 4b). Compared to the crystalline component, the amorphous component has elevated $\mathrm{Al}_{2} \mathrm{O}_{3}$, similar $\mathrm{TiO}_{2}$ and $\mathrm{SiO}_{2}$, and lower $\mathrm{Fe}_{\text {Total. }}$. Using FULLPAT, the amorphous material is modeled with various allophane compositions (69.3 wt \% total) and ferrihydrite (21.1 wt\%, Table S4).

The amorphous + clay component composition for the paleosol sample (TC-1) is essentially the same whether the sample contained an internal standard or not when measured on the PANalytical 


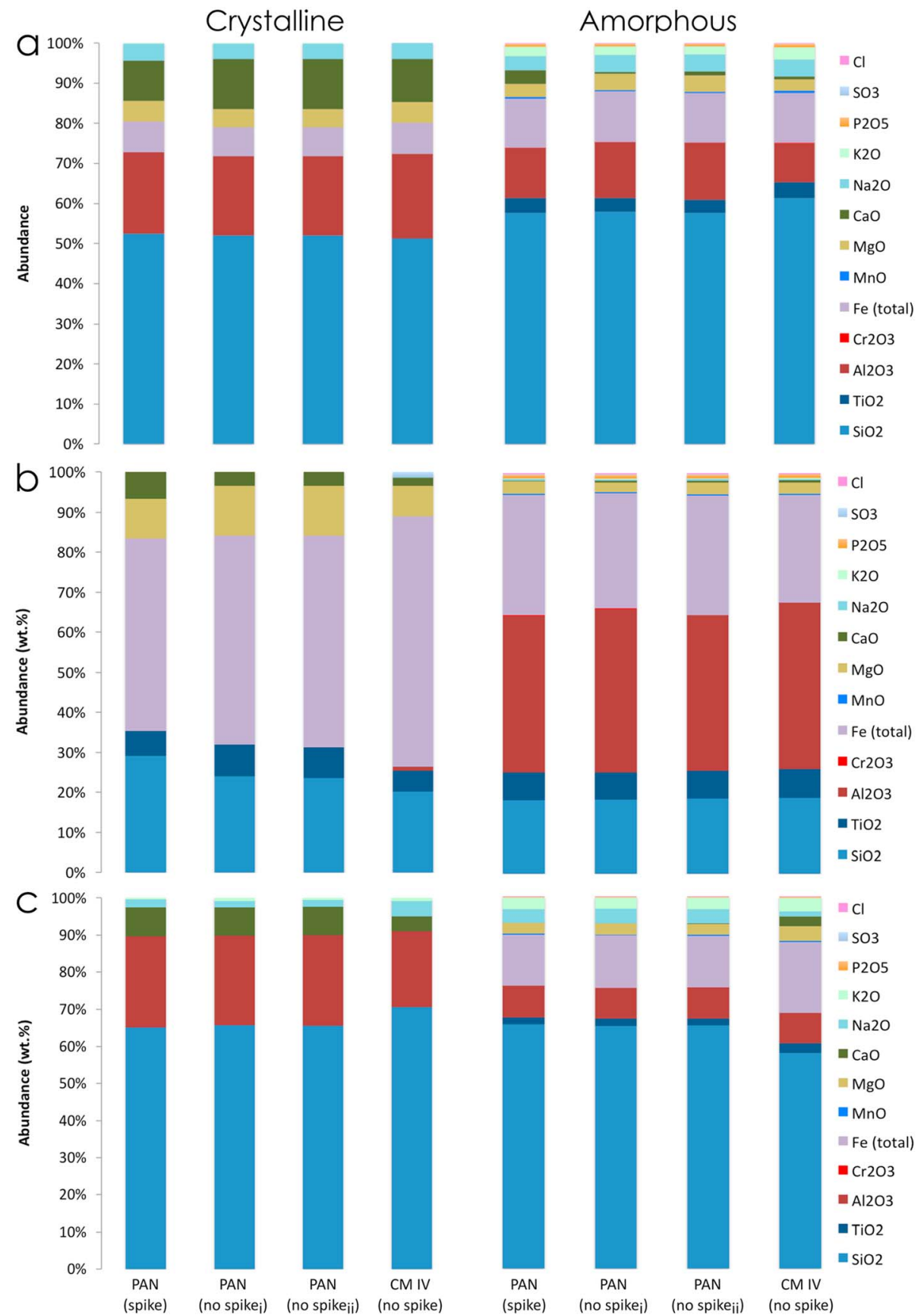

Figure 4. Composition of crystalline (best estimate mineralogy) and amorphous components calculated using the mass balance equation for the glacial sediment (160814X; a), Hawaiian soil (2-Laupahoehoe; b), and paleosol (TC-1; c) samples using data from the different measurement techniques. PAN refers to samples measured on the PANalytical instrument, while CM IV refers to samples measured on the CheMin IV instrument. (i) The Rietveld refinement was performed using the nominal density, and (ii) the refinement was performed using the calculated density found in Table S5. Amorphous composition for TC-1 includes clay minerals. Abundances for each component (amorphous or crystalline) are normalized to $100 \%$. See Table S5 in the supporting information for numerical results and equation input details.

instrument (Figure 4c). The amorphous + clay component composition for the sample measured on the CheMin IV instrument has lower $\mathrm{SiO}_{2}$ and higher $\mathrm{CaO}$ abundances than the components of samples measured on the PANalytical. The $\mathrm{SiO}_{2}$ discrepancy is mostly a result of a lower amorphous abundance $\left(x_{a m o r p h}\right)$ used in the MBC for the CheMin pattern. If we use an amorphous abundance closer to that of 
the PANalytical not spiked data (56 wt\%), the $\mathrm{SiO}_{2}$ is increased to levels similar to the PANalytical MBC results. The $\mathrm{CaO}$ discrepancy is due to the different plagioclase (andesine) compositions used in the MBCs (Table S3). Overall, the amorphous + clay component has lower $\mathrm{Al}_{2} \mathrm{O}_{3}$ and $\mathrm{CaO}$ and similar $\mathrm{SiO}_{2}$ to the crystalline component, but all of the $\mathrm{Fe}_{\mathrm{Total}}, \mathrm{TiO}_{2}, \mathrm{MgO}$, and $\mathrm{K}_{2} \mathrm{O}$ are found in the amorphous component. Using FULLPAT, the amorphous material is modeled with basaltic glass (5.6 wt\%), allophanes (7.9 wt\% total), and ferrihydrite (0.6 wt\%, Table S4).

We can compare the calculated densities of amorphous materials to densities of the amorphous materials modeled in the FULLPAT analyses. The amorphous materials used in the FULLPAT models are basaltic glass $\left(3.0 \mathrm{~g} / \mathrm{cm}^{3}\right)$, ferrihydrite $\left(>\sim 3.0 \mathrm{~g} / \mathrm{cm}^{3}\right.$; Eggleton \& Fitzpatrick, 1988), and allophane $\left(\sim 2.7 \mathrm{~g} / \mathrm{cm}^{3} ;\right.$ Wada \& Wada, 1977). Using the above densities, sample $160814 \mathrm{X}$ would have an average amorphous material density of $3.0 \mathrm{~g} / \mathrm{cm}^{3}$, compared to the calculated density of $2.3 \mathrm{~g} / \mathrm{cm}^{3}$. Using FULLPAT amorphous materials, 2Laupahoehoe would have an amorphous material density of $2.8 \mathrm{~g} / \mathrm{cm}^{3}$, compared to the calculated density of $1.34 \mathrm{~g} / \mathrm{cm}^{3}$. The density of clay minerals can vary with composition, but using an average density for montmorillonite $\left(\sim 2.7 \mathrm{~g} / \mathrm{cm}^{3}\right.$; Wada \& Wada, 1977), the FULLPAT amorphous + clay component for sample TC-1 would yield a density of $\sim 2.7 \mathrm{~g} / \mathrm{cm}^{3}$, which is slightly lower than the calculated density of $3.05 \mathrm{~g} / \mathrm{cm}^{3}$.

\section{Discussion}

\subsection{Effects of Mineralogy on the Estimated Abundance of Amorphous Components}

Since the outputs of Rietveld refinements (amorphous and crystalline abundances and crystalline composition) are used as inputs for the mass balance calculations, the MBC results (amorphous abundance and composition) can serve as a check on the quality of the Rietveld refinement. For example, the abundance of amorphous component in the 2-Laupahoehoe sample is underestimated in the Rietveld refinement of the sample measured without an internal standard on the CheMin IV instrument. Yet when the relative mineral abundances and compositions from the refinement are used as inputs in the mass balance calculation, the amorphous component abundance is much closer to that estimated with an internal standard. There are two major ways that the refinement quality can affect the calculated or modeled amorphous abundance: the accuracy of (1) the full-pattern fitting outputs (modeled mineralogy) and (2) the model input/refined parameters associated with the amorphous component and background. Section 5.2 will discuss the potential effects of model inputs/refined paramters on the amorphous component.

Amorphous abundances derived from the MBC method are driven by the crystalline mineralogy (both composition and abundance) modeled in the full-pattern fitting analysis. Chemically realistic amorphous component compositions are obtained by increasing the amorphous abundance until all oxides in the amorphous component have positive abundances. Doing so adjusts only the absolute abundances of the crystalline minerals, assuming that their relative abundances and compositions are correctly modeled in the refinement. If there is an oxide that is in low abundance in the bulk sample, but modeled in high abundance in the crystalline component, the crystalline material must make up a smaller fraction of the sample as a whole. For example, pyrite $\left(\mathrm{FeS}_{2}\right)$ is modeled at $\sim 1 \mathrm{wt} \%$ in the refinement of the 2-Laupahoehoe sample measured on the CheMin IV without an internal standard. However, the abundance of $\mathrm{SO}_{3}$ in the bulk sample is very low (0.16 wt\%), so in order to have an amorphous component composition with $\mathrm{SO}_{3} \geq 0 \mathrm{wt} \%$, the amorphous component fraction must be increased significantly. In contrast, when sing the modeled mineralogy of the 2-Laupahoehoe sample from patterns measured on the PANalytical instrument, the calculated amorphous abundances are driven by the amount of $\mathrm{CaO}$ in the crystalline component. As stated above, pyrite is most likely substituting for ilmenite as a result of the restricted angular range of the CheMin IV instrument, so that an important ilmenite peak is not measured. Thus, a large discrepancy between the Rietveld and MBC estimate can elucidate an error in the refinement.

\subsection{Effects of Model Parameters on the Estimated Abundance of Amorphous Component}

Differences in amorphous abundance between measurements cannot always be easily attributed to differences in modeled crystalline mineralogy. For example, when measured on the PANalytical instrument, the relative mineral abundances modeled for the glacial sediment sample (160814X) using Rietveld refinements are similar whether the sample was measured with or without an internal standard. However, the amorphous abundance modeled in the refinement of the data without an internal standard is higher than the abundance 
determined from the internal standard method. This indicates that there is a factor other than mineralogy affecting the amorphous abundance modeled in the refinement.

Here we show that the model parameters that have the greatest effect on the estimated amorphous abundance are (1) the amorphous material properties (assigned density when using Jade and scattering power when using FULLPAT), (2) the modeled amorphous peak area, and (3) the modeled background. When no internal standard is included in the measurement, the amorphous abundance remains inversely dependent on the assigned density (or scattering power) of the amorphous material, because peak intensity is directly proportional to the density (or scattering power). Thus, assuming too high of a density (or scattering power) will cause the amorphous abundance to be underestimated. Unfortunately, it is not possible to know the correct density to use when no internal standard is included in the sample, when the amorphous phases have not been definitively identified using other techniques such as transmission electron microscopy or when the amorphous component is a complex mixture of materials. Furthermore, unlike crystalline phases, the densities (and scattering powers) of X-ray amorphous materials are poorly studied and not well characterized.

Given the same amorphous material density, a larger modeled amorphous peak will produce a greater modeled abundance of amorphous material; however, the size of the amorphous peak is also dependent on the modeled background. The background in an XRD pattern is mostly a result of scattering caused by incoherent radiation, fluorescent radiation, temperature-diffuse scattering, and apparatus-dependent factors (e.g., incident beam and air scatter; Van der Gaast \& Vaars, 1981). Amorphous and poorly crystalline materials also produce a significant amount of diffuse scattering because they lack periodic atomic distribution; so unfortunately, broad amorphous peaks are sometimes difficult to distinguish from the background (Rowe \& Brewer, 2018). Thus, if the background were overestimated, the amorphous abundance could be underestimated.

The amorphous abundance calculated for the not spiked $160814 \mathrm{X}$ sample using the nominal density $\left(2.5 \mathrm{~g} / \mathrm{cm}^{3}\right)$ is overestimated when compared to the internal standard method. The nominal density is slightly higher than the calculated density of $2.3 \mathrm{~g} / \mathrm{cm}^{3}$, but this should cause the amorphous abundance to be underestimated. Additionally, the areas above the background are relatively similar ( $25.2 \%$ for the not spiked sample and $28.3 \%$ for the spiked sample; Table S6). Thus, it is more likely that there is a difference in the modeled amorphous peak area. In fact, the amorphous peak area for the not spiked sample is much greater (37.0\%) than the amorphous peak area for the spiked sample (27.3\%; Table S6). When the calculated density is used to determine the amorphous abundance in the refinement of the not spiked sample, we should expect an amorphous abundance similar to the internal standard method, but they are not similar. The amorphous peak area modeled in the refinement of the not spiked sample (36.6\%; Table S6) is much higher than that of the spiked sample, and so the amorphous abundance is overestimated. Thus, in this case, the discrepancies in Rietveldderived amorphous abundances are mostly due to the differences in modeled amorphous peak areas.

It is much more difficult to determine the source of the amorphous abundance discrepancies across all methods for the Hawaiian soil sample (2-Laupahoehoe). This could be due to the fact that this sample is modeled with two distinct amorphous peaks $\left(\sim 30^{\circ} 2 \theta\right.$ and $\left.\sim 45^{\circ} 2 \theta\right)$ to account for the two prominent broad peaks seen in allophane patterns (e.g., Rampe et al., 2013). More free parameters allows more discrepancy between models, and the amorphous peak areas and areas above the backgrounds are highly variable between refinements (Table S6). For example, the areas under the amorphous peaks using the calculated density for the not spiked PANalytical data are much higher than for the spiked sample $(56.0 \%$ and $80.1 \%$ versus $33.2 \%$ and $58.4 \%$ ), which should also produce much higher amorphous abundance values. However, the area above the background for the not spiked sample (4.1\%) is approximately half that of the spiked sample ( $8 \%$ ), and so it is possible that a higher modeled background for the not spiked sample helped reduce the effect of the amorphous peak areas (Table S6). Ultimately, the amorphous abundance derived using the calculated density for the not spiked PANalytical data is very similar to that found using the internal standard method, so these effects appear to even each other out. Instead, the discrepancies in Rietveld refinement-derived amorphous abundances in this case appear to be due to differences in the assigned amorphous material density, as the nominal density $\left(2.5 \mathrm{~g} / \mathrm{cm}^{3}\right)$ is much higher than the calculated density $\left(1.34 \mathrm{~g} / \mathrm{cm}^{3}\right)$. For both not spiked PANalytical pattern refinements, the modeled amorphous peak areas are the same $(56.0 \%$ and $80.1 \%)$, but when the amorphous abundance is estimated using the calculated density, the value is much closer to that of the internal standard method. Thus, the discrepancies in Rietveld refinement-derived amorphous abundances in this case are most likely due to differences in the assigned amorphous material density. 
Both of the unspiked paleosol (TC-1) refinements of the pattern measured on the PANalytical overestimate the abundance of amorphous + clay material when compared to the internal standard method, regardless of density used. Additionally, all PANalytical data are modeled with similar backgrounds. Thus, the overestimations must be due to the modeled areas of the amorphous peaks. Indeed, the amorphous peak areas modeled in the not spiked data are much higher (44.3\% using nominal density and $46.2 \%$ using calculated density) than the amorphous peak area modeled in the spiked sample (24.4\%). When the calculated density $\left(3.05 \mathrm{~g} / \mathrm{cm}^{3}\right)$ is used, the amorphous + clay abundance is slightly closer to the internal standard method, as would be expected.

For the nonclay-bearing samples, the bulk amorphous material densities from FULLPAT analyses $\left(3.0 \mathrm{~g} / \mathrm{cm}^{3}\right.$ for $160814 \mathrm{X}$ and $2.8 \mathrm{~g} / \mathrm{cm}^{3}$ for 2-Laupahoehoe) are higher than the densities calculated from the Rietveld refinements of spiked data $\left(2.3 \mathrm{~g} / \mathrm{cm}^{3}\right.$ for $160814 X$ and $1.34 \mathrm{~g} / \mathrm{cm}^{3}$ for 2-Laupahoehoe). Since material density is directly proportional to scattering power, we would expect that amorphous abundances calculated from too high of densities would be underestimated when compared to the internal standard method, and this is indeed the case for FULLPAT models of $160814 \mathrm{X}$ and 2-Laupahoehoe. The amorphous + clay material density estimated from the FULLPAT analysis of TC-1 $\left(\sim 2.7 \mathrm{~g} / \mathrm{cm}^{3}\right)$ is slightly lower than the calculated density $\left(3.05 \mathrm{~g} / \mathrm{cm}^{3}\right)$, which results in an overestimate of amorphous + clay abundance when compared to the internal standard method.

Our results show that amorphous abundances are highly dependent on the modeled area of the amorphous peaks, the fit of the background, and the amorphous material density. In particular, a possible pitfall is assuming a nominal density for amorphous materials in not spiked measurements, as the range in possible densities is large enough to potentially affect the calculated amorphous abundance. But this may be unavoidable when working with unspiked and poorly constrained samples, and the effect is generally small enough that the results are still useful. In most cases, Rietveld refinements of samples measured without an internal standard on common XRD (PANalytical) instruments provide amorphous abundances (within 15\% error of the spiked sample). In general, we find that FULLPAT does a good job of quantifying the amorphous abundance of samples measured without an internal standard (within $5 \%$ error of the spiked sample)

\subsection{Effects of Parent Material and Weathering Environment on the Compositions of Amorphous Materials}

$\mathrm{CaO}$ and $\mathrm{MgO}$ abundances show significant variations when comparing amorphous material compositions calculated for a single sample. This potentially highlights difficulties in modeling accurate Ca- and Mgbearing phases in a Rietveld refinement analysis, especially in mafic terrains where these elements are concentrated. Care should be taken when these phases are present.

General compositional trends for the amorphous and crystalline counterparts are consistent with the expectations for the locations and weathering environments for each sample. The amorphous and crystalline components for the glacial sediment sample (160814X) have similar compositions, indicating either a significant volcanic glass component with chemistry similar to the bulk composition, which would be consistent with FULLPAT results, or weathering with little preferential loss of ions from the system. The slightly elevated $\mathrm{SiO}_{2}$ and $\mathrm{Fe}_{\text {Total }}$ abundances in the amorphous component could be evidence for the later.

The Hawaiian soil sample (2-Laupahoehoe) is from a relatively young lava flow (20 kyr) in a region of high rainfall $(2,500 \mathrm{~mm} /$ year) that has been shown to result in initial weathering to allophane (Chorover et al., 2004; Ziegler et al., 2003). The amorphous composition of the sample is enriched in $\mathrm{Al}_{2} \mathrm{O}_{3}$ with some $\mathrm{Fe}_{2} \mathrm{O}_{3}$, consistent with high abundances of allophane and moderate ferrihydrite, as is modeled in the FULLPAT analysis.

FULLPAT results suggest that the composition of the amorphous + clay component of the paleosol sample (TC-1) is dominated by the clay component; clay minerals (modeled as montmorillonite and saponite) combine to a total of $38.2 \mathrm{wt} \%$ out of the $52.3 \mathrm{wt} \%$ amorphous + clay abundance, leaving only $14.1 \mathrm{wt} \%$ amorphous material. Overall, the amorphous + clay component composition is very similar to the composition of the amorphous component of the glacial sample (160814X), but unlike the glacial sample, very little volcanic glass is modeled in the FULLPAT analysis of TC-1 (5.6 wt\%). No Fe-bearing phases are modeled in the crystalline component of TC-1 despite the intermediate nature of the parent material (andesitic pyroclastic deposit; Retallack et al., 1999). The clay mineral most likely contains some of the iron in the sample, but 
the rest is in the amorphous component, potentially as hisingerite or ferrihydrite. Overall, these results indicate that the amorphous component composition can be reasonably estimated using the MBC method, but that determining the actual amorphous assemblage present most likely requires more in depth investigations like transmission electron microscopy.

\subsection{Implications for the CheMin Instrument on Mars}

For complex natural samples, FULLPAT analyses of CheMin IV data are generally capable of providing good mineral and amorphous estimates when compared to traditional laboratory XRD methods, despite not using an internal standard in the sample preparation. These results are consistent with those from Blake et al. (2012) who tested CheMin IV against laboratory XRD methods for a handful of natural samples including one amorphous-bearing Hawaiian tephra sample. In addition, FULLPAT analyses appear to produce more accurate results than Rietveld refinements for CheMin IV data. It is unclear why Rietveld refinements of CheMin IV data do not always produce amorphous abundance estimates similar to that of the samples measured on the PANalytical instrument without an internal standard. Major differences in instrumentation include the following: CheMin measures a sample in transmission (Debye-Scherrer) geometry while PANalytical measures in reflective (Bragg-Brentano) geometry; PANalytical has a finer angular resolution $\left(0.02^{\circ}\right.$ versus $0.3^{\circ}$ for CheMin); CheMin (IV) has a smaller angular range of measurement $\left(\sim 2^{\circ}-55^{\circ} 2 \theta\right)$ than PANalytical $\left(\sim 2^{\circ}-150^{\circ}\right.$ $2 \theta$ ); CheMin (IV) instrumentation constantly vibrates the sample, while the sample is stationary during the PANalytical measurement so that preferred orientation of minerals may affect patterns measured on the PANalytical.

Since CheMin measurements do not include an internal standard, it is possible that amorphous abundance discrepancies could occur if care is not taken with regard to the density of the amorphous materials and the background and amorphous peak areas used during Rietveld refinement. For example, the amorphous abundance modeled in the Rietveld refinement of 2-Laupahoehoe CheMin IV data is much lower than that derived from the Rietveld refinement of all samples measured on the PANalytical instrument. Additionally, while a basaltic glass composition is relatively consistent with the calculated amorphous + clay composition for TC-1 (Figure 4c), it seems unlikely that basaltic glass is a significant component of an ancient soil due to its relative instability under surface conditions on Earth. Thus, the basaltic glass modeled in the FULLPAT analysis might be substituting for another amorphous material. Until the patterns of a wide range of amorphous materials are measured on the CheMin IV, it is recommended to use both the full-pattern fitting and the MBC methods to estimate the amorphous component abundance and composition. Doing so could illuminate potential inaccuracies with the mineralogy models and/or the assumed amorphous material properties.

\section{Conclusions}

Three methods are commonly used to estimate the abundance of the amorphous component of samples from XRD patterns: (1) Rietveld refinement, (2) FULLPAT, and (3) mass balance calculations (MBCs). In this study we have tested the accuracy of these methods by comparing derived amorphous abundances and compositions across techniques and instruments.

The results from this work show that the MBC method can be very useful in determining the bulk amorphous abundance and composition, gauging the accuracy of the XRD models, and adjusting for problems in the refinements. This method is used regularly for characterizing the amorphous component in Martian samples but is infrequently used for terrestrial samples. Terrestrial studies of natural amorphous materials more frequently rely on selective dissolution methods, which are limited in only characterizing the chemically reactive portions of the amorphous component. Our results indicate that terrestrial studies could be improved by also applying the MBC method.

Additionally, our results highlight the importance of using an internal standard in laboratory XRD analyses when the sample contains amorphous phases. In most cases, when samples are measured with an internal standard, the crystalline and amorphous abundances estimated using Rietveld refinements produce chemically realistic amorphous compositions using the $M B C$ method, suggesting that these refinements are accurate. When samples are measured without using an internal standard, the overall crystalline mineralogy determined via Rietveld refinement is still accurate, but the Rietveld refinement will either overestimate or underestimate the amorphous abundance because of inaccurate assumptions of amorphous material 
density or problems with the fit of the amorphous hump(s) and/or background. We find that FULLPAT analyses of patterns without an internal standard produce reasonable amorphous abundances, but the types of amorphous materials identified with FULLPAT may not be reasonable because of the limited number of amorphous patterns in the library. Thus, if it is not possible to include an internal standard in laboratory XRD analyses of samples containing amorphous phases, we recommend using both the full-pattern fitting and the MBC methods together to constrain the amorphous component abundance.

Regardless of whether or not an internal standard is included in the sample, the composition of the calculated amorphous component is generally consistent across analyses and techniques. However, the accuracy of the amorphous composition in all techniques is negatively affected by inaccuracies in the modeled crystalline mineralogy. The amorphous composition ends up taking in leftover elements that were improperly excluded in the crystalline assemblage, due to either incorrect mineral compositions or minerals that were not included in the models because they are present below detection limits.

Overall, CheMin analog measurements perform well in our tests of samples, and amorphous abundances from the Rietveld refinements and FULLPAT analyses are comparable to laboratory quantitative XRD measurements, even though they do not include an internal standard, although Rietveld refinements of CheMin IV data tend to underestimate amorphous abundances. This suggests that previous estimates of amorphous component abundances and compositions derived for Martian samples are relatively accurate though abundances derived from Rietveld refinements might be underestimates, and large discrepancies between Rietveld and MBC abundances should be regarded with some skepticism. The presence of clay minerals in our terrestrial sample does not significantly affect the amorphous + clay abundance or composition, and so we can assume that amorphous abundances and compositions for Martian clay-bearing samples are also relatively accurate. However, since CheMin does not include an internal standard in the sample processing, it is possible that inaccurate amorphous abundances could result if care is not taken with regard to identifying the correct amorphous materials, because of the effects of material density.

Acknowledgments

This work was funded by the NASA Mars Science Laboratory Participating Scientist Program and the NASA Solar System Workings Program. We would like to thank Cliff Johnston and Darrel Schulze for use of their XRD facilities at Purdue University, Oliver Chadwick for providing Hawaiian soil samples, Greg Retallack for guidance in collecting and analyzing paleosol samples, Noel Scudder, Alicia Rutledge, and Marie McBride for intrepid assistance with collecting and analyzing the glacial sediment samples, Shaunna Morrison for help with deriving chemical compositions from unit cell parameters, Amy McAdam for the evolved gas analysis of sample TC- 1 found in the supporting information, Valerie Tu for help with particle size measurements and XRD instrument setup, and the MSL science team for helpful comments and encouragement. This manuscript was significantly improved with input from Steve Chipera and an anonymous reviewer. Data used in this paper can be found in the supporting information document.

\section{References}

Achilles, C. N., Downs, R. T., Ming, D. W., Rampe, E. B., Morris, R. V., Treiman, A. H., et al. (2017). Mineralogy of an active eolian sediment from the Namib dune, Gale crater, Mars. Journal of Geophysical Research: Planets, 122, 2344-2361. https://doi.org/10.1002/2017JE005262

Achilles, C. N., Downs, R. T., Rampe, E. B., Morris, R. V., Bristow, T. F., Ming, D. W., et al. (2017). The amorphous composition of three mudstone samples from Gale Crater: Implications for weathering and diagenetic processes on Mars. Geological Society of America Annual Meeting, Seattle, WA 49(6). https://doi.org/10.1130/abs/2017AM-305666

Achilles, C. N., Morris, R. V., Chipera, S. J., Ming, D. W., \& Rampe, E. B. (2013). X-ray diffraction reference intensity ratios of amorphous and poorly crystalline phases: Implications for CheMin on the Mars Science Laboratory Mission. In Lunar and Planetary Science Conference XLIV. Houston, TX, Abstract 3072.

Alexander, L., \& Klug, H. P. (1948). Basic aspects of X-ray absorption in quantitative diffraction analysis of powder mixtures. Analytical Chemistry, 20(10), 886-889. https://doi.org/10.1021/ac60022a002

Birrell, K., \& Fieldes, M. (1952). Allophane in volcanic ash soils. Journal of Soil Science, 3(2), 156-166. https://doi.org/10.1111/j.1365-2389.1952. tb00639.x

Bish, D. L., Blake, D. F., Vaniman, D. T., Chipera, S. J., Morris, R. V., Ming, D. W., et al. (2013). X-ray diffraction results from Mars science laboratory: Mineralogy of Rocknest at Gale crater. Science, 341(6153), 1238932. https://doi.org/10.1126/science.1238932

Bish, D. L., \& Howard, S. A. (1988). Quantitative phase analysis using the Rietveld method. Journal of Applied Crystallography, 21(2), 86-91. https://doi.org/10.1107/s0021889887009415

Blake, D., Vaniman, D., Achilles, C., Anderson, R., Bish, D., Bristow, T., et al. (2012). Characterization and calibration of the CheMin mineralogical instrument on Mars science laboratory. Space Science Reviews, 170(1-4), 341-399. https://doi.org/10.1007/s11214-012-9905-1

Blake, D. F., Morris, R. V., Kocurek, G., Morrison, S. M., Downs, R. T., Bish, D., et al. (2013). Curiosity at Gale crater, Mars: Characterization and analysis of the Rocknest sand shadow. Science, 341(6153), 1239505. https://doi.org/10.1126/science.1239505

Borggaard, O. K. (1988). Phase identification by selective dissolution techniques. In J. W. Stucki, B. A. Goodman, \& U. Schwertmann (Eds.), Iron in soils and clay minerals NATO ASI series C: Mathematical and physical sciences (Vol. 217, pp. 83-98). Dordrecht: Springer. https://doi.org/ 10.1007/978-94-009-4007-9_5

Chadwick, O. A., Derry, L. A., Vitousek, P. M., Huebert, B. J., \& Hedin, L. O. (1999). Changing sources of nutrients during four million years of ecosystem development. Nature, 397(6719), 491-497. https://doi.org/10.1038/17276

Chipera, S. J., \& Bish, D. L. (2002). FULLPAT: A full-pattern quantitative analysis program for X-ray powder diffraction using measured and calculated patterns. Journal of Applied Crystallography, 35(6), 744-749. https://doi.org/10.1107/s0021889802017405

Chipera, S. J., \& Bish, D. L. (2013). Fitting full X-ray diffraction patterns for quantitative analysis: A method for readily quantifying crystalline and disordered phases. Advances in Materials Physics and Chemistry, 03(01), 47-53. https://doi.org/10.4236/ampc.2013.31 A007

Chorover, J., Amistadi, M. K., \& Chadwick, O. A. (2004). Surface charge evolution of mineral-organic complexes during pedogenesis in Hawaiian basalt. Geochimica et Cosmochimica Acta, 68(23), 4859-4876. https://doi.org/10.1016/j.gca.2004.06.005

Chung, F. H. (1974). Quantitative interpretation of X-ray diffraction patterns of mixtures. I. Matrix-flushing method for quantitative multicomponent analysis. Journal of Applied Crystallography, 7(6), 519-525. https://doi.org/10.1107/S0021889874010375

Copeland, R. H., \& Bragg, R. H. (1958). Quantitative X-ray diffraction analysis. Analytical Chemistry, 30(2), 196-201. https://doi.org/10.1021/ ac60134a011 
Dehouck, E., McLennan, S. M., Meslin, P.-Y., \& Cousin, A. (2014). Constraints on abundance, composition, and nature of X-ray amorphous components of soils and rocks at Gale crater, Mars. Journal of Geophysical Research: Planets, 119, 2640-2657. https://doi.org/10.1002/ 2014JE004716

DeMumbrum, L. E. (1960). Crystalline and amorphous soil minerals of the Mississippi coastal terrace ${ }^{1}$. Soil Science Society of America Journal, 24(3), 185-189. https://doi.org/10.2136/sssaj1960.03615995002400030018x

Eggleton, R. A., \& Fitzpatrick, R. W. (1988). New data and a revised structural model for ferrihydrite. Clays and Clay Minerals, 36(2), 111-124. https://doi.org/10.1346/CCMN.1988.0360203

Gellert, R., \& Clark, B. C, and the MSL and MER Science Teams (2015). In situ compositional measurements of rocks and soils with the alpha particle X-ray spectrometer on NASA's Mars rovers. Elements, 11(1), 39-44. https://doi.org/10.2113/gselements.11.1.39

Gellert, R., Rieder, R., Brückner, J., Clark, B. C., Dreibus, G., Klingelhöfer, G., et al. (2006). Alpha particle X-ray spectrometer (APXS): Results from Gusev crater and calibration report. Journal of Geophysical Research, 111, E02S05. https://doi.org/10.1029/2005JE002555

Grotzinger, J. P., Sumner, D. Y., Kah, L. C., Stack, K., Gupta, S., Edgar, L., et al. (2014). A Habitable Fluvio-Lacustrine Environment at Yellowknife Bay, Gale Crater, Mars. Science, 343, 1242777. https://doi.org/10.1126/science.1242777

Hooton, D. H., \& Giorgetta, N. E. (1977). Quantitative X-ray diffraction analysis by a direct calculation method. X-Ray Spectrometry, 6(1), $2-5$. https://doi.org/10.1002/xrs.1300060103

Horgan, B. H. N., Smith, R. J., Chadwick, O. A., Retallack, G. J., Noe Dobrea, E., \& Christensen, P. R. (2017). The effects of climate, environment, and diagenesis on the spectral properties of volcanic soils. In Geological Society of America Cordilleran Section - 113th Annual Meeting. Hawai'i. https://doi.org/10.1130/abs/2017CD-292837

Ishii, J., \& Mori, T. (1959). Studies on the clay in volcanic ash soil in Ishiyama, near Sapporo. The Journal of the Geological Society of Japan, 65(765), 357-363. https://doi.org/10.5575/geosoc.65.357

Jackson, M. L., Lim, C. H., \& Zelazny, L. W. (1986). Oxides, hydroxides, and aluminosilicates. In A. Klute (Ed.), Methods of Soil Analysis, Part 1 : Physical and Mineralogical Methods, Agronomy 9 (2nd ed., pp. 101-150). Madison, Wl: American Society of Agronomy.

Jones, R. C., Babcock, C. J., \& Knowlton, W. B. (2000). Estimation of the total amorphous content of Hawai'i soils by the Rietveld method. Soil Science Society of America Journal, 64(3), 1100-1108. https://doi.org/10.2136/sssaj2000.6431100x

Klug, H., \& Alexander, L. (1974). X-ray diffraction procedures for polycrystalline and amorphous materials (2nd ed.). New York: John Wiley.

Leshin, L. A., Mahaffy, P. R., Webster, C. R., Cabane, M., Coll, P., Conrad, P. G., et al. (2013). Volatile, Isotope, and Organic Analysis of Martian Fines with the Mars Curiosity Rover. Science, 341(6153), 1238937. https://doi.org/10.1126/science.1238937

Mitchell, B. D., \& Farmer, V. C. (1960). Amorphous clay minerals in some Scottish soil profiles. Clay Minerals, 5(28), 128-144. https://doi.org/ 10.1180/claymin.1962.005.28.08

Moore, D., \& Reynolds, R. (1997). X-ray diffraction and the identification and analysis of clay minerals (2nd ed.). New York: Oxford University Press.

Morris, R. V., Ming, D. W., Blake, D. F., Vaniman, D. T., Bish, D. L., Chipera, S. J., et al. (2013). The amorphous component in Martian basaltic soil in global perspective from MSL and MER missions. In Lunar and Planetary Science Conference XLIV. Houston, TX, Abstract 1653.

Morris, R. V., Vaniman, D. T., Blake, D. F., Gellert, R., Chipera, S. J., Rampe, E. B., et al. (2016). Silicic volcanism on Mars evidenced by tridymite in high-SiO2 sedimentary rock at Gale crater. Proceedings of the National academy of Sciences of the United States of America, 113(26), 7071-7076. https://doi.org/10.1073/pnas.1607098113

Morrison, S. M., Downs, R. T., Blake, D. F., Prabhu, A., Eleish, A., Vaniman, D. T., et al. (2018). Relationships between unit-cell parameters and composition for rock-forming minerals on earth, Mars, and other extraterrestrial bodies. American Mineralogist, 103(6), 848-856. https:// doi.org/10.2138/am-2018-6123

Morrison, S. M., Downs, R. T., Blake, D. F., Vaniman, D. T., Ming, D. W., Hazen, R. M., et al. (2018). Crystal chemistry of Martian minerals from Bradbury landing through Naukluft Plateau, Gale crater, Mars. American Mineralogist, 103(6), 857-871. https://doi.org/10.2138/am2018-6124

Rampe, E., Horgan, B., Scudder, N., Smith, R. J., \& Rutledge, A. (2017). Mineralogy of rock flour in glaciated volcanic terrains: An analog for a cold and icy early Mars. In Lunar and Planetary Science Conference XLVIII. Houston, TX, Abstract 2437.

Rampe, E. B., Bish, D. L., Chipera, S. J., Morris, R. V., Achilles, C. N., Ming, D. W., et al. (2013). Detecting nanophase weathering products with CheMin: Reference intensity ratios of allophane, aluminosilicate gel, and ferrihydrite. In Lunar and Planetary Science Conference XLIV. Houston, TX, Abstract 1188 .

Rampe, E. B., Ming, D. W., Blake, D. F., Bristow, T. F., Chipera, S. J., Grotzinger, J. P., et al. (2017). Mineralogy of an ancient lacustrine mudstone succession from the Murray formation, Gale crater, Mars. Earth and Planetary Science Letters, 471, 172-185. https://doi.org/10.1016/j. epsl.2017.04.021

Retallack, G. J., Bestland, E. A., \& Fremd, T. J. (1999). Eocene and Oligocene Paleosols of Central Oregon, Geological Society of America.

Rietveld, H. M. (1969). A profile refinement method for nuclear and magnetic structures. Journal of Applied Crystallography, 2(2), 65-71. https://doi.org/10.1107/s0021889869006558

Rowe, M. C., \& Brewer, B. J. (2018). AMORPH: A statistical program for characterizing amorphous materials by X-ray diffraction. Computers \& Geosciences, 120, 21-31. https://doi.org/10.1016/j.cageo.2018.07.004

Schwertmann, U., \& Fischer, W. R. (1973). Natural "amorphous" ferric hydroxide. Geoderma, 10(3), 237-247. https://doi.org/10.1016/00167061(73)90066-9

Scilab Enterprises (2014). Scilab: Free and open source software for numerical computation. Retrieved from http://www.scilab.org/

Scudder, N., Horgan, B., Havig, J., Rutledge, A., Rampe, E. B., \& Hamilton, T. (2016). Differentiating hydrothermal, pedogenic, and glacial weathering in a cold volcanic Mars-analog environment. In Lunar and Planetary Science Conference XLVII. Houston, TX, Abstract 2937.

Scudder, N., Rutledge, A., Horgan, B., \& Rampe, E. (2017). A Mars analog for wet-based glacial alteration of volcanic terrains: Visible and nea infrared remote sensing at Three Sisters, Oregon, U.S.A. In Sixth International Conference on Mars Polar Science and Exploration, Iceland, Abstract 6093.

Simas, F. N. B., Schaefer, C. E. G. R., Guerra, M. B. B., Melo, V. F., Saunders, M., \& Gilkes, R. J. (2006). Clay-sized minerals in permafrostaffected soils (Cryosols) from King George Island, Antarctica. Clays and Clay Minerals, 54(6), 721-736. https://doi.org/10.1346/CCMN. 2006.0540607

Sudo, T. (1954). Clay mineralogical aspects of the alteration of volcanic glass in Japan. Clay Minerals Bulletin, 2(11), 96-106. https://doi.org/ 10.1180/claymin.1954.002.11.02

Treiman, A. H., Bish, D. L., Vaniman, D. T., Chipera, S. J., Blake, D. F., Ming, D. W., et al. (2016). Mineralogy, provenance, and diagenesis of a potassic basaltic sandstone on Mars: CheMin X-ray diffraction of the Windjana sample (Kimberley area, Gale crater). Journal of Geophysical Research: Planets, 121, 75-106. https://doi.org/10.1002/2015JE004932 
Van Dam, R. L., Harrison, J. B. J., Hirschfeld, D. A., Meglich, T. M., Li, Y., \& North, R. E. (2008). Mineralogy and magnetic properties of basaltic substrate soils: Kaho'olawe and big island, Hawaii. Soil Science Society of America Journal, 72(1), 244. https://doi.org/10.2136/ sssaj2006.0281

Van Der Gaast, S. J., \& Vaars, A. J. (1981). A method to eliminate the background in X-ray diffraction patterns of oriented clay mineral samples. Clay Minerals, 16(04), 383-393. https://doi.org/10.1180/claymin.1981.016.4.07

Vaniman, D. T., Bish, D. L., Ming, D. W., Bristow, T. F., Morris, R. V., Blake, D. F., et al. (2014). Mineralogy of a mudstone at Yellowknife Bay, Gale crater, Mars. Science, 343(6169), 1243480. https://doi.org/10.1126/science.1243480

Wada, S.-I., \& Wada, K. (1977). Density and structure of allophane. Clay Minerals, 12, 289-289.

Warren, B. (1990). X-ray diffraction (Dover ed., Dover books on physics ed.). New York: Dover Publications.

Yen, A. S., Ming, D. W., Vaniman, D. T., Gellert, R., Blake, D. F., Morris, R. V., et al. (2017). Multiple stages of aqueous alteration along fractures in mudstone and sandstone strata in Gale crater, Mars. Earth and Planetary Science Letters, 471, 186-198. https://doi.org/10.1016/j. epsl.2017.04.033

Ziegler, K., Hsieh, J. C. C., Chadwick, O. A., Kelly, E. F., Hendricks, D. M., \& Savin, S. M. (2003). Halloysite as a kinetically controlled end product of arid-zone basalt weathering. Chemical Geology, 202(3-4), 461-478. https://doi.org/10.1016/j.chemgeo.2002.06.001 